\title{
LA POBREZA EN SANTA MARTA: LOS ESTRAGOS DEL BIEN
}

\author{
ADOLFO MEISEL-ROCA \\ DIANA RICCIULLI-MARIN*
}

\begin{abstract}
RESUMEN
En 1985, el indicador de pobreza por Necesidades Básicas Insatisfechas (NBI) posicionó a Santa Marta como la ciudad con menor pobreza entre las ocho capitales de la Región Caribe. Dos décadas más tarde, en 2005, Santa Marta empeoró su desempeño relativo, alcanzando un NBI superior al de otras capitales de la región como Barranquilla y Cartagena. Este documento tiene tres objetivos principales: primero, realizar una caracterización espacial de la pobreza en Santa Marta; segundo, investigar las razones del rezago relativo en reducción de pobreza; y tercero, proponer una serie de inversiones para superar dicho rezago. El análisis encuentra que el retroceso se debe en buena parte a la llegada masiva de desplazados que se inició en la década de 1990. Por su parte, los mapas muestran la aparición de cinturones de miseria en las faldas de los cerros aledaños y en algunas zonas del perímetro urbano, donde la pobreza coincide con la informalidad y el bajo logro educativo. Estos y otros resultados revelan prioridades de inversión en cuatro sectores: educación, vivienda, acueducto y alcantarillado, y empleo.
\end{abstract}

\footnotetext{
* Los autores son, en su orden, Rector de la Universidad del Norte, en Barranquilla, y Economista del Centro de Estudios Económicos Regionales (CEer), del Banco de la República, en Cartagena. Correos electrónicos: ameisel@uninorte.edu.co y driccima@banrep.gov.co. Una primera versión de este trabajo fue publicada con el mismo título en la Serie de Trabajos sobre Economía Regional y Urbana, del Centro de Estudios Económicos Regionales (CEER), Banco de la República, No. 206, abril de 2018. Los autores agradecen los comentarios de Jaime Bonet, gerente del Banco de la República en Cartagena; Joaquín Viloria, gerente del Banco de la República en Santa Marta; y Julio Romero, economista del CEer. Recibido: julio 4 de 2018; aceptado: noviembre 9 de 2018.
}

Economía \& Región, Vol. 12, No. 2, (Cartagena, diciembre 2018), pp. 43-105. 
Palabras clave: Región Caribe colombiana, Santa Marta, pobreza, educación.

Clasificación JEL: I32, I38, R23.

\begin{abstract}
Poverty in Santa Marta, Colombia: A Case Study

In 1985, Santa Marta was the city with the lowest level of structural poverty in the Colombian Caribbean region according to the index of Unsatisfied Basic Needs (UBN). Two decades later, in 2005, Santa Marta worsened its relative performance, with an index of UBN greater than other cities of the region such as Cartagena and Barranquilla. This paper has three purposes. First, to characterize poverty and its spatial dimension in Santa Marta. Second, to understand the causes of the lag in poverty reduction. And third, to propose a set of investments to overcome this lag. Our analysis shows that one of the main factors associated with increased poverty in the city was the massive arrival of displaced people, starting in the 1990's. The maps, meanwhile, show the appearance of misery belts in the surrounding foothills and in some areas inside the urban perimeter, where poverty is correlated with informality and low educational attainment. These and other results point to investment priorities in four sectors: education, housing, water and sewage, and employment.
\end{abstract}

Key words: Colombian Caribbean region, Santa Marta, poverty, education.

JEL Classification: I32, I38, R23.

\title{
I. INTRODUCCIÓN
}

Es cierto que éste es un pueblo de chismosos y envidiosos, pero nunca hubo asesinos ni criminales hasta que llegaron esos bandidos que utilizan el nombre del pueblo para robar, para ultrajar, para abusar, para acabar con siglos enteros de lucha y trabajo. Es que en nombre del bien siempre se termina haciendo mal

Alonso Sánchez Baute, Líbranos del bien (2008)

Santa Marta fue la primera ciudad fundada por los españoles en Suramérica. Después de la independencia y hasta 1870 fue el principal puerto de la actual 
Colombia. A comienzos del siglo xx, con el auge de exportaciones de banano del departamento de Magdalena y la presencia de la United Fruit Company, la ciudad tuvo unas décadas de prosperidad. Después del retiro de esta compañía en 1965, el banano pasó a jugar un papel menos importante y el turismo, inicialmente centrado en la bahía de El Rodadero, se convirtió en la principal fuente de crecimiento económico.

Según el Departamento Administrativo Nacional de Estadística (DANE), en 2016 el valor agregado de Santa Marta alcanzó los 5,4 billones de pesos, equivalente al 43\% del Producto Interno Bruto (PIB) del departamento del Magdalena. En ese año, las dos ramas de actividad económica con mayor participación fueron los servicios comunales, sociales y personales, y el comercio, los hoteles y restaurantes. En su conjunto, estas dos ramas representaron el 53\% de toda la actividad productiva de la ciudad.

A pesar de no contar con cifras desagregadas para la actividad turística, algunos datos permiten entrever su importancia. Cifras de la Asociación Hotelera y Turística de Colombia (COTELCO) indican que en enero de 2018 la ocupación hotelera en el departamento de Magdalena fue de 68\%, la tercera más alta después de San Andrés y Bolívar. En ese mismo mes, el Parque Tayrona recibió alrededor de 400.000 turistas, siendo el segundo parque nacional natural más visitado de país. Por otro lado, en 2017 el aeropuerto Simón Bolívar de Santa Marta fue el segundo, después de San Andrés, con un mayor crecimiento en el número de pasajeros aéreos nacionales (Ministerio de Comercio, Industria y Turismo - MinciT, 2018).

Además de la transformación económica, desde un sector primario dominado por el banano a uno terciario representado en el turismo, Santa Marta vivió un importante crecimiento demográfico, concentrado principalmente en su zona urbana. Entre 1985 y 1993, según los censos de población de dichos años, la tasa de crecimiento promedio anual de su población fue de 2,7\%, frente a un 1,4\% para el total nacional. En ese mismo período, la población urbana del departamento aumentó su participación de $82 \%$ a $85 \%$ del total, mientras que la rural caía de $18 \%$ a $15 \%$.

A pesar de que la terciarización económica y la rápida urbanización son fenómenos comúnmente asociados al progreso y desarrollo de una sociedad, en Santa Marta estos se relacionaron con la persistencia de la pobreza y las desigualdades económicas y sociales. Entre 1985 y 1993, mientras el turismo y la población urbana crecían, la ciudad experimentaba un retroceso en materia de bienestar. En este período, la pobreza medida por Necesidades Básicas Insatisfechas (NBI) pasó del 33\% al 34\%. Lo anterior sucedió cuando en otras ciudades, como Cartagena 
y Barranquilla, se observaban caídas cercanas a los 10 puntos porcentuales en ese mismo indicador.

Este deterioro en las condiciones de vida coincidió con la llegada de la violencia al territorio. Como menciona el escritor Alonso Sánchez Baute en su libro Libranos del bien: "[...] llegaron esos bandidos que utilizan el nombre del pueblo para robar, para ultrajar, para abusar, para acabar con siglos enteros de lucha y trabajo. Es que en nombre del bien siempre se termina haciendo mal". Los indicadores de pobreza revelan que la lucha por el "bien" no acabó con las desigualdades sociales y por el contrario, ocasionó estragos en las condiciones de vida de la población.

Aunque la pobreza en los barrios periféricos de Cartagena ha recibido mucha atención de los medios de comunicación, académicos y, en cierta medida, de la dirigencia local, el caso de Santa Marta, que supera en los distintos índices de pobreza a la situación de Cartagena, ha sido poco discutido. El presente documento ayuda a llenar ese vacío, estudiando la pobreza y los principales problemas asociados a ella en Santa Marta. Con esto, además de darle una mayor visibilidad a este asunto, el trabajo constituye una herramienta que permite avanzar en las políticas de superación de la pobreza en la ciudad.

El estudio aborda el tema de la pobreza desde una perspectiva espacial, usando los mapas como principal herramienta de análisis. Además, examinando algunos antecedentes históricos, ofrece un primer acercamiento a las principales razones del rezago de la ciudad. El documento se divide en cinco secciones. La segunda presenta los antecedentes históricos. La tercera examina la pobreza y sus principales indicadores. La cuarta analiza la situación de la educación en la ciudad. La quinta presenta una serie de propuestas para superar el rezago en materia de pobreza en 2030. Finalmente, la última sección desarrolla las conclusiones del trabajo.

\section{ANTECEDENTES HISTÓRICOS}

La década de 1960 fue de recomposición de la economía de Santa Marta. En la primera mitad del siglo xx, el motor de su crecimiento fue la exportación de banano (Viloria, 2014). El tope más alto en el valor de las exportaciones bananeras de la llamada "Zona Bananera de Santa Marta" se alcanzó en 1956, con usD \$156,7 millones. De allí en adelante las exportaciones declinaron y para 1970 solo alcanzaban a ser USD \$3,4 millones (Meisel, 2005).

El declive de la economía bananera en el departamento del Magdalena se inició a fines de la década de 1950, con la venta gradual de tierras y activos que hizo 
la United Fruit Company. Al final, en 1965, la empresa se retiró totalmente del Magdalena y trasladó su operación a Urabá, Antioquia, donde había empezado a exportar banano desde 1964 (Bucheli, 2005).

Otro cambio económico estructural de la economía samaria en la década de 1960 fue el ascenso de la actividad turística. En 1959 se inauguró el moderno Hotel Tamacá, en una bahía aledaña a Santa Marta, en la zona conocida como El Rodadero. En los siguientes años se construyeron en esta zona otros hoteles y muchos edificios de apartamentos, que fueron adquiridos para fines recreativos por personas oriundas de Barranquilla y de otras partes de Colombia. A este auge turístico contribuyó la inauguración, en 1960, de la carretera Ciénaga-Barranquilla, que se consolidó con la inauguración, en abril de 1974, del Puente Pumarejo, sobre el río Magdalena. Estas últimas inversiones facilitaron el acceso a El Rodadero desde Barranquilla y, por lo tanto, el turismo de fines de semana.

En la década de 1970, se observó también un importante crecimiento del turismo procedente de Venezuela. Este estaba constituido en su mayoría por personas de altos ingresos que llegaban con frecuencia a visitar la Quinta de San Pedro Alejandrino, donde murió Simón Bolívar. A mediados de los 70 y principios de los 80 , este turismo se vería reducido por el incremento de la inseguridad en la carretera entre Maicao y Santa Marta.

En el período intercensal 1964 - 1973, Santa Marta fue una ciudad de bajo crecimiento demográfico, si se compara con Barranquilla o Cartagena. Como se muestra en el Gráfico 1, en ese período la ciudad creció a una tasa de 3,67\% por año. En el siguiente período intercensal, 1973 - 1985, su crecimiento poblacional fue intermedio entre Cartagena y Barranquilla. Sin embargo, en los años más recientes (período intercensal 1993 - 2005), su crecimiento fue de 3,86\%, más del doble de Barranquilla (1,29\%) y superior al de Cartagena (2,99\%).

Uno de los elementos principales que explica el marcado contraste en términos demográficos de estas tres ciudades es el influjo de desplazados que recibió Santa Marta desde la década de 1990, especialmente en razón del conflicto armado que se vivió en las zonas rurales de los departamentos de Magdalena y Cesar. Según el censo de 2005, aproximadamente el $70 \%$ de quienes llegaron a la ciudad tenían como lugar de origen estos dos departamentos (Cuadro 1).

Aunque las cifras sobre desplazados en Colombia son siempre motivo de controversia, estas sirven para observar las tendencias más amplias. De acuerdo con el Registro Único de Víctimas (RUV), en términos absolutos Santa Marta fue la tercera ciudad en recibir más desplazados en el periodo 1985 - 2017, solo superada por Bogotá y Medellín, ciudades con poblaciones mucho más grandes (Gráfico 2). 


\section{GRÁFICO 1 \\ Barranquilla, Cartagena y Santa Marta:}

Tasa de crecimiento promedio anual de la población, 1964 - 2005

(porcentajes)

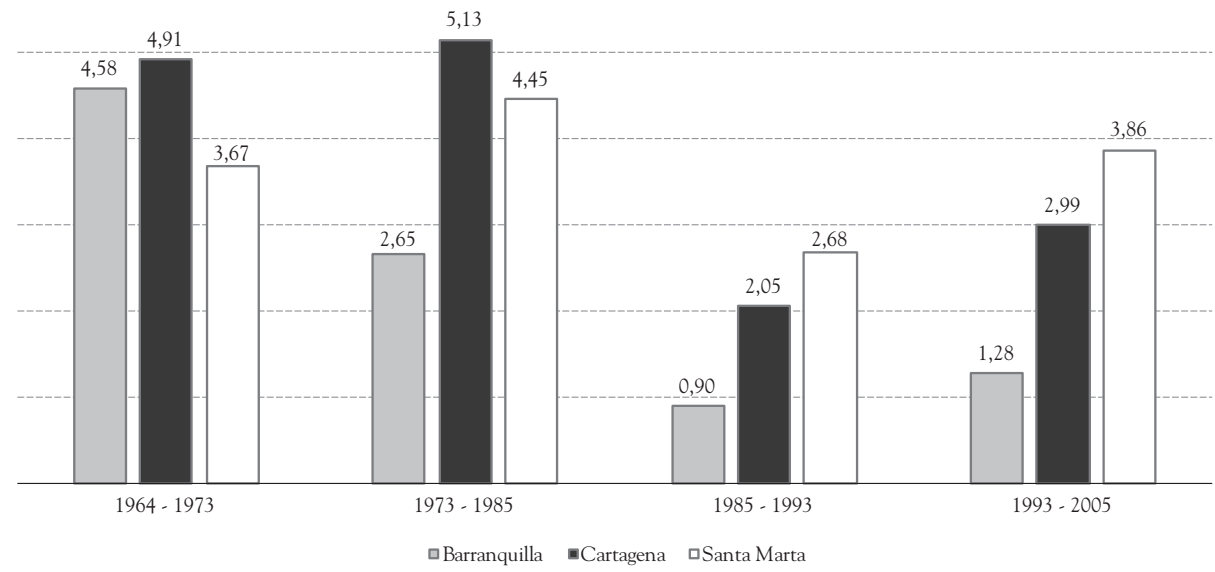

Fuentes: Elaboración propia con base en los censos de población del DANE.

\section{CUADRO 1}

Santa Marta: Departamentos de origen de sus inmigrantes, 2005

\begin{tabular}{|l|c|}
\hline \multicolumn{1}{|c|}{ Departamento } & Porcentaje \\
\hline Magdalena & 63,4 \\
\hline Cesar & 6,4 \\
\hline Atlántico & 5,5 \\
\hline Santander & 4,1 \\
\hline Bolivar & 3,3 \\
\hline La Guajira & 2,9 \\
\hline Antioquia & 2,6 \\
\hline Bogotá & 2,5 \\
\hline Otros & 9,3 \\
\hline
\end{tabular}

Fuentes: Elaboración propia con base en datos del censo de 2005. 


\section{GRÁFICO 2}

23 ciudades principales e intermedias de Colombia:

Número de desplazados recibidos, 1985 - 2017

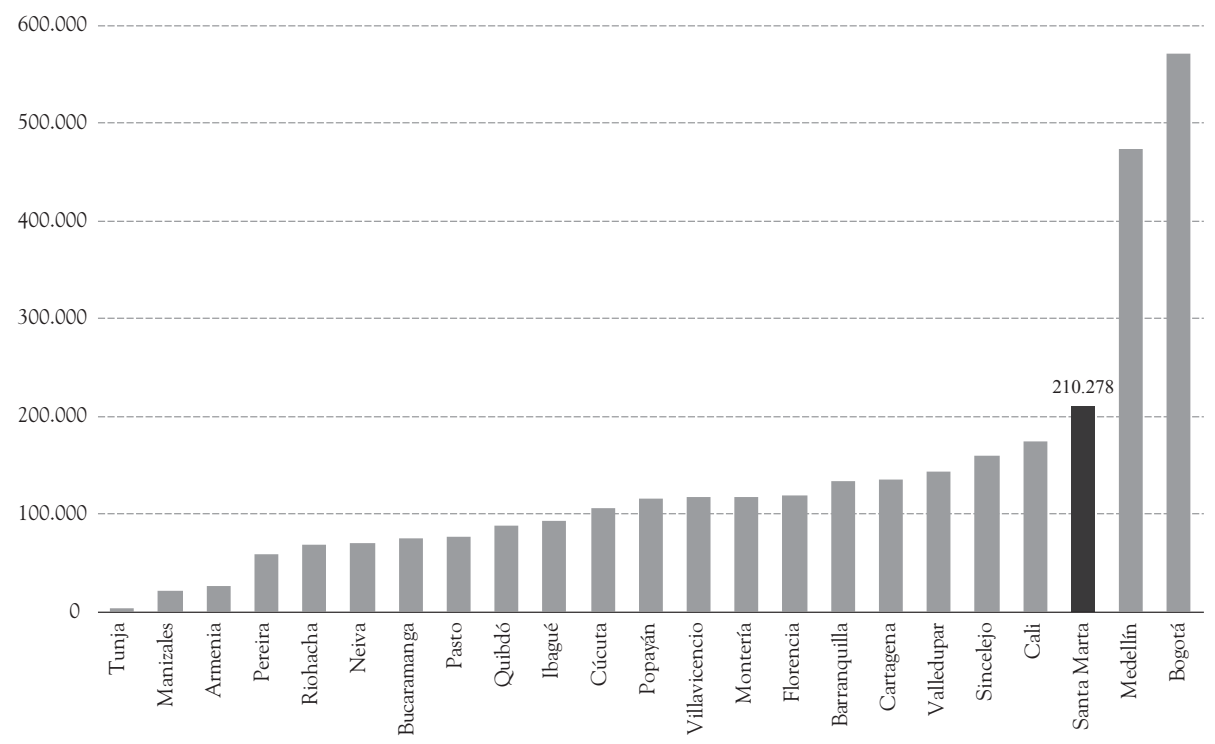

Fuente: Registro Único de Víctimas (RUV).

A partir de esta misma fuente de datos se puede observar que la mayoría de los desplazados que llegaron a Santa Marta lo hicieron entre los años 2000 y 2008 , es decir cuando el conflicto armado estaba en su punto más alto (Gráfico 3).

Uno de los obstáculos que debían enfrentar los desplazados al llegar a la ciudad eran las dificultades para acceder a una vivienda. En 1997, se hablaba de un déficit de viviendas en Santa Marta de entre 10.000 y 12.000 unidades. En un seminario sobre las ciudades del Caribe organizado por el Observatorio del Caribe Colombiano en 2009, en la discusión sobre el caso de Santa Marta se le dio gran relevancia al tema de los desplazados: “...la población desplazada que llega a Santa Marta crece diariamente y agudiza el déficit de vivienda. En los actuales momentos esta constituye una situación crítica al incrementar los índices de pobreza y reducir el nivel de vida de los asentamientos poblacionales existentes" (Abello y Giaimo, 2000).

Como se muestra en la siguiente sección, el gran crecimiento demográfico y la llegada masiva de desplazados a Santa Marta resultaron en un aumento relativo 


\section{GRÁFICO 3}

Santa Marta: Número de desplazados, 1985 - 2017

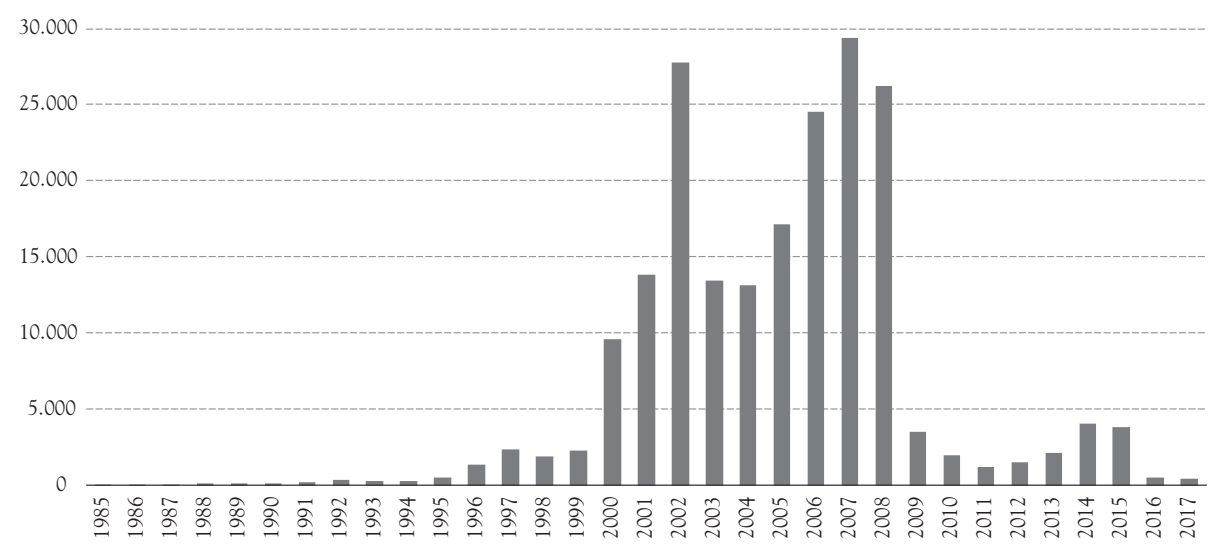

Fuente: RUV.

de la pobreza con respecto a otras ciudades de Colombia. Los indicadores de acceso a servicios públicos, condiciones de empleo, vulnerabilidad ambiental y educación revelan la falta de una adecuada respuesta del gobierno local para proveer a la población de bienes y servicios públicos básicos. La consecuencia fue la aparición de cinturones de miseria en las faldas de los cerros y algunas zonas del casco urbano.

\section{POBREZA EN SANTA MARTA}

El crecimiento poblacional acelerado, sumado a la escasez de bienes y servicios básicos, ha traído consigo nuevas formas de pobreza a las sociedades urbanas. Más allá de la insuficiencia de ingresos, en estas nuevas dinámicas la pobreza es consecuencia de la privación de necesidades básicas, que les impide a las personas evitar el hambre y la desnutrición, acceder a una educación de calidad y, en general, lograr unas condiciones mínimas de vida (Sen, 1984). La exclusión social aparece aquí como un concepto dominante, que, en general, se asocia con la inhabilidad de algunas personas para participar en las actividades económicas y sociales disponibles para la mayoría de la población (Levitas, et al., 2007). Santa Marta no ha sido ajena a estos procesos. De hecho, la variedad de problemas que 
se viven en la ciudad encajan muy bien en esta visión multidimensional. Desde esta perspectiva, a continuación se ofrece una primera aproximación al estudio de la pobreza y sus principales dimensiones en la ciudad.

Hay dos tipos de enfoque en la medición de la pobreza. El primero está relacionado con la insuficiencia de recursos para satisfacer una serie de necesidades básicas. El segundo, por su parte, depende del consumo efectivamente realizado o las necesidades realmente satisfechas (Feres y Mancero, 2001). Dentro del primer enfoque se usa el indicador de pobreza monetaria, que clasifica como pobres a los hogares cuyo ingreso promedio se encuentra por debajo de un mínimo necesario que permite acceder a una canasta de bienes y servicios básicos (DANE, 2017). En el segundo se cubren tres indicadores: Necesidades Básicas Insatisfechas (NBI), Índice de Pobreza Multidimensional (IPM) y un índice de exclusión social. El primero evalúa cinco dimensiones: calidad de la vivienda, acceso a servicios públicos básicos, hacinamiento crítico, asistencia escolar y dependencia económica. El segundo, además de considerar lo anterior, incluye otras 10 dimensiones, dentro de las cuales se adicionan los temas de salud, empleo y condiciones de vida en la niñez y la juventud. Por último, a partir del estudio de Ayala y Meisel (2016), se calcula un índice de exclusión social, que comprende en total 12 indicadores relacionados con las condiciones de vida en la niñez y la juventud, el empleo, la educación, la salud y la seguridad en el entorno. ${ }^{1}$

\section{A. Principales indicadores}

A pesar de una reducción importante en el porcentaje de personas con NBI en Santa Marta, el período 1973 - 2005 comprende décadas de avances y retrocesos en materia de pobreza. En 1973 y 1985 la ciudad vivió un progreso importante, reduciendo su pobreza en 12 puntos porcentuales (pp) y alcanzando una incidencia de $33 \%$, lo que la llevó a posicionarse como la menos pobre en comparación con Cartagena y Barranquilla. No obstante, en los ochos años siguientes esta ten-

${ }^{1}$ El índice de exclusión social se construye mediante un análisis de componentes principales que incluye las siguientes 12 variables: embarazo adolescente, rendimiento académico, tasa de mortalidad infantil, tasa de desempleo, tasa de analfabetismo, proporción de la población que no aporta a pensión, pobreza moderada, pobreza extrema, tasa de homicidios, expectativa de vida al nacer, disponibilidad de bienes y servicios básicos, y desigualdad de ingresos. 
dencia se revertiría. Para 1993, el porcentaje de personas con necesidades básicas insatisfechas en Santa Marta se estimaba en 34\%, lo que la hacía la más pobre de estas tres ciudades. Este posicionamiento se mantuvo en los años siguientes (Gráfico 4).

El enfoque directo de pobreza monetaria reafirma estas tendencias. Según cifras del DANE para 2017, el 33\% de la población en Santa Marta vive en condición de pobreza monetaria. Esto indica que cerca de 164.799 samarios tienen ingresos mensuales por debajo de la línea de pobreza, que para el caso de Santa Marta es de cop $\$ 275.724$. Con esta cifra, la ciudad se ubica por encima del total nacional; entre las 23 ciudades principales e intermedias es la sexta con mayor incidencia, superando a Quibdó, Riohacha, Florencia, Cúcuta y Valledupar (Gráfico 5).

Si se comparan estas cifras con las de siete años atrás, no hay evidencia de grandes avances. El Gráfico 6 muestra la incidencia de la pobreza monetaria en 2010. A pesar de una reducción de 7 pp entre 2010 y 2017, la posición de Santa

\section{GRÁFICO 4}

Barranquilla, Cartagena y Santa Marta:

Incidencia de la pobreza por NBI, 1973 - 2005

(porcentajes)

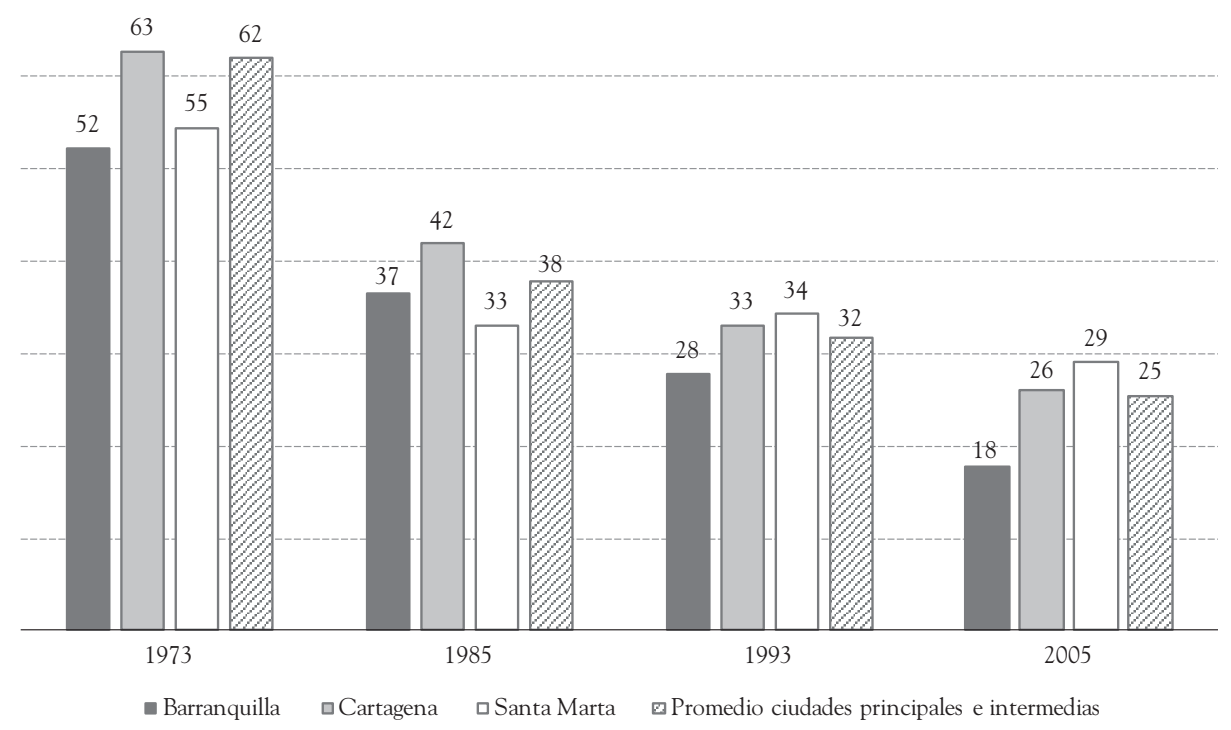

Fuentes: Galvis y Meisel (2010) y censos de población del DANE. 


\section{GRÁFICO 5}

23 ciudades principales e intermedias de Colombia:

Incidencia de la pobreza monetaria, 2017

(porcentajes)

50

40

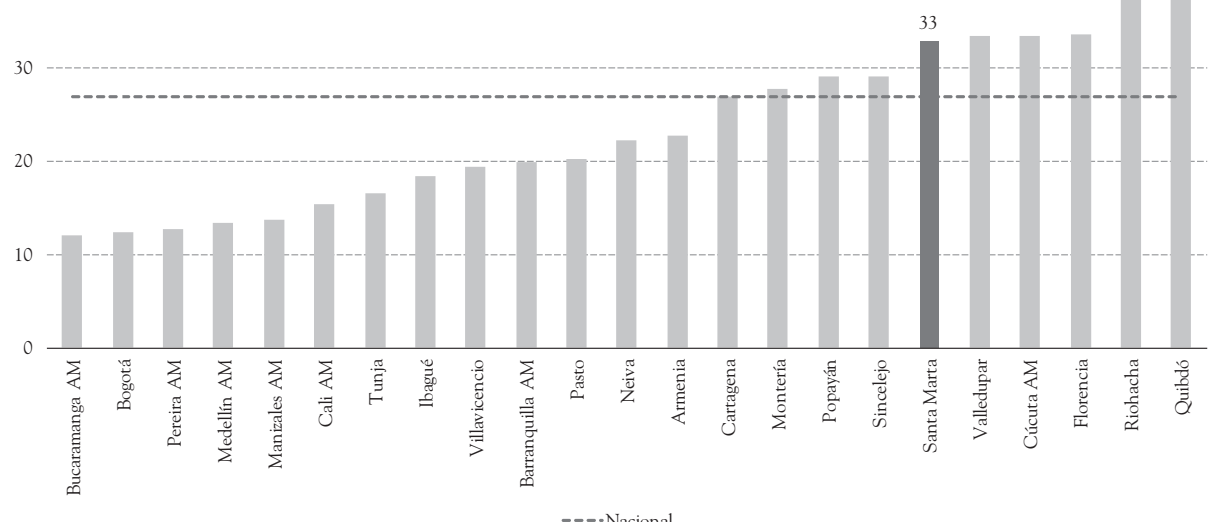

Fuentes: Elaboración propia con base en datos de la Gran Encuesta Integrada de Hogares (GEIH) del DANE.

GRÁFICO 6

23 ciudades principales e intermedias de Colombia:

Incidencia de la pobreza monetaria, 2010

(porcentajes)

60

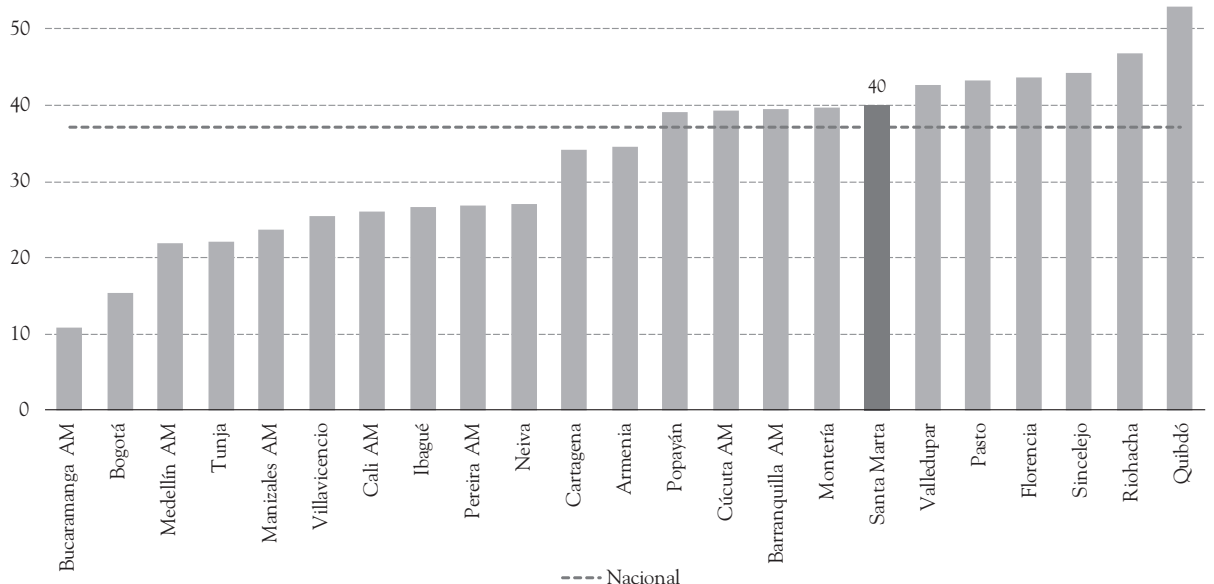

Nota: AM: Área Metropolitana.

Fuentes: Elaboración propia con base en datos de la GEIH del DANE. 
Marta frente a otras ciudades ha empeorado. En 2010, la situación de pobreza en la ciudad era similar a las de Barranquilla y Montería. Siete años más tarde, estas dos ciudades redujeron su pobreza, acercándose más al total nacional y, en el caso de la primera, superándolo. Santa Marta, en contraste, se acercó más a las dos ciudades en peor situación, Riohacha y Quibdó.

El retroceso es evidente, incluso si se diferencia lo urbano de lo rural. Cuando se trata de la cabecera municipal, Santa Marta ocupa el quinto lugar con mayor incidencia de pobreza; por su parte, en el caso del resto del municipio, la ciudad mejora una posición, ubicándose en el sexto lugar (Gráfico 7). Finalmente, un aspecto a resaltar de todas las ciudades, a excepción de Quibdó, es la mayor incidencia de pobreza en las zonas rurales.

Las ventajas en acceso a servicios básicos, como salud y educación, así como la infraestructura física y social que ofrecen las zonas urbanas, son factores que ayudan a explicar parte de estas brechas (Sanghee, 2017). No obstante, es importante destacar que la menor incidencia en las cabeceras no necesariamente es señal

\section{GRÁFICO 7}

23 ciudades principales e intermedias de Colombia:

Incidencia de la pobreza por NBI, cabeceras y resto, 2005

(porcentajes)

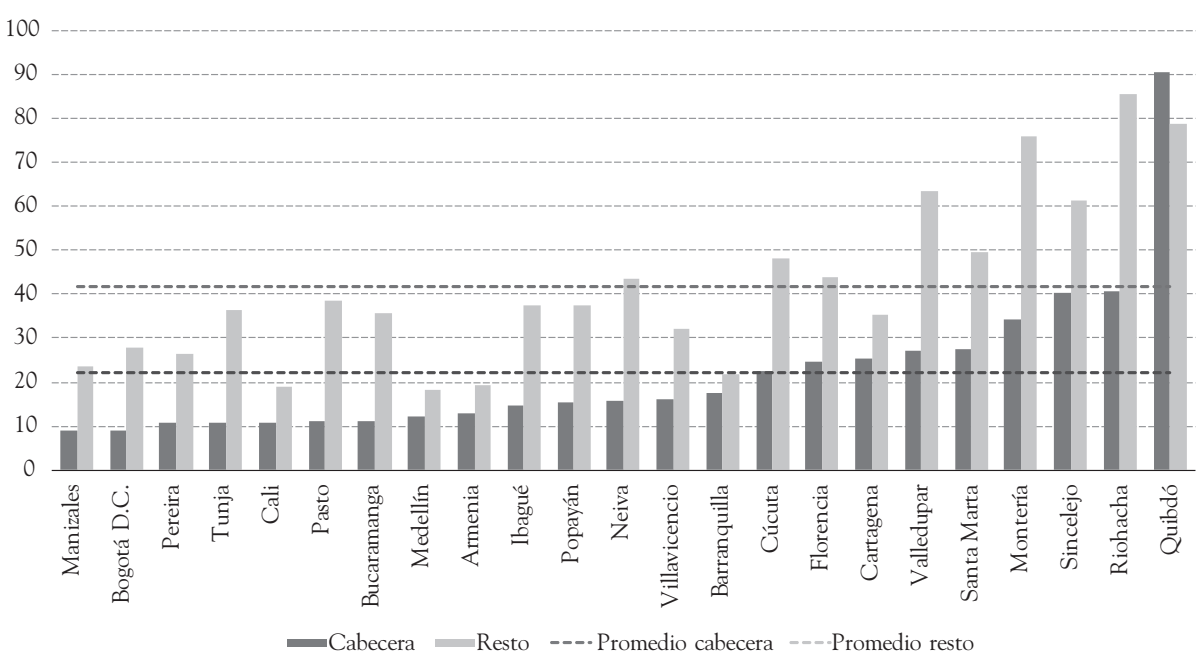

Fuentes: Elaboración propia con base en datos del censo de 2005 del DANE. 
de mejores condiciones de vida en estas zonas. Los habitantes de las cabeceras suelen enfrentarse en mayor medida a otro tipo de problemas, como la exclusión social, la segregación espacial y la vulnerabilidad ambiental. De hecho, una de las grandes diferencias respecto a las zonas rurales es la coexistencia de estos problemas con la proximidad física a la riqueza, los servicios y las oportunidades (Fay y Ruggeri, 2005).

Santa Marta, al ser una sociedad urbana, se acerca mucho a la descripción anterior. Para mayor claridad es preciso mirar las dimensiones que más inciden en la pobreza en la ciudad. En el Gráfico 8 se presentan las 15 dimensiones del

\section{GRÁFICO 8}

Santa Marta: Dimensiones del IPM, 2005

(porcentajes)

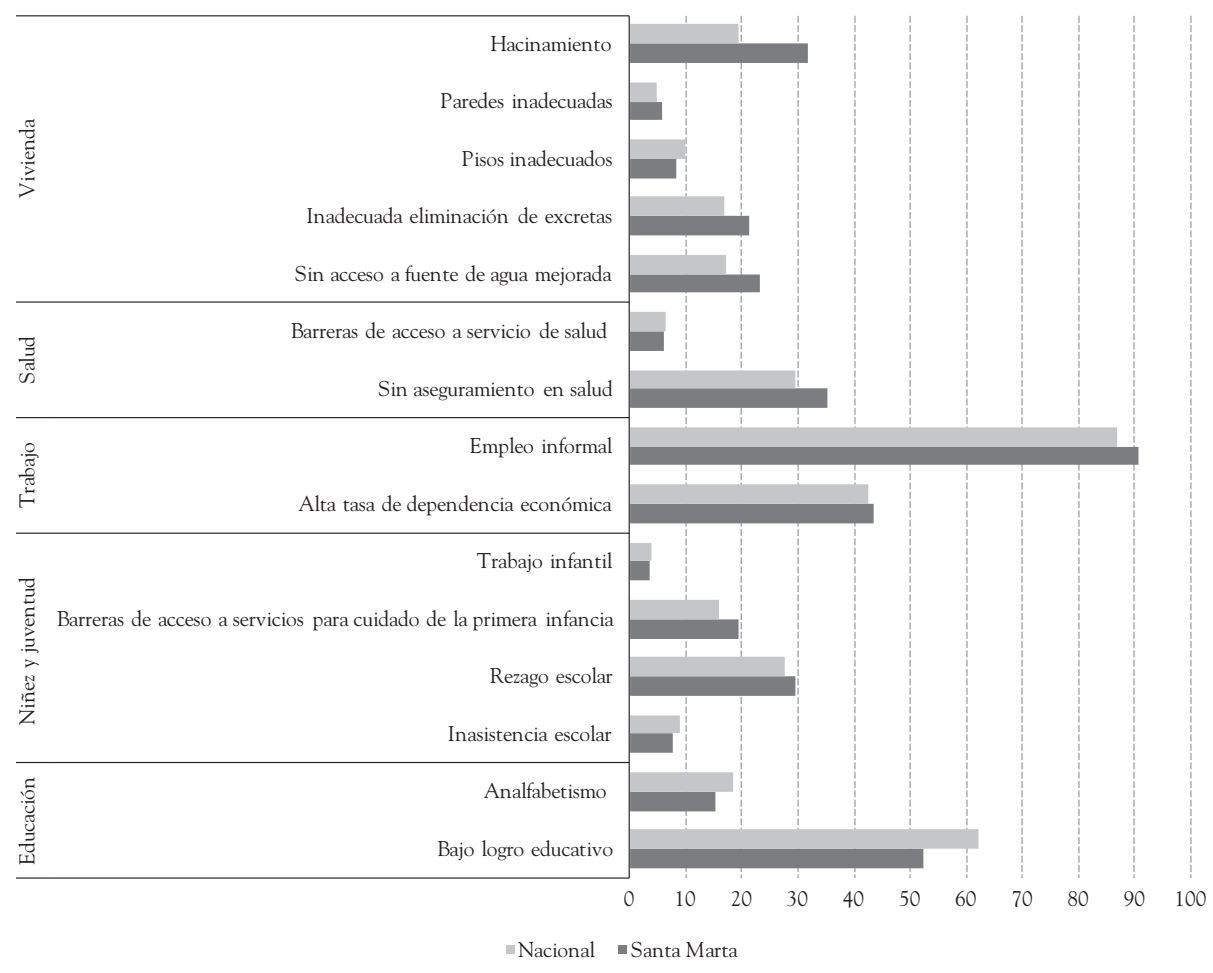

Fuentes: Elaboración propia con base en datos de DNP. 
IPM para Santa Marta y el total nacional en 2005. En ambos casos, la dimensión con mayor incidencia en la pobreza es el empleo informal, seguido del bajo logro educativo y la alta dependencia económica. De otra parte, y consistente con las ventajas que ofrecen las cabeceras, se presenta una baja incidencia de otras dimensiones como las barreras de acceso a servicios de salud y la inasistencia escolar. Además, el hacinamiento crítico es el componente que presenta el mayor rezago con respecto al total nacional.

Finalmente, se calcula el índice de exclusión social para las 23 ciudades principales e intermedias. Los tres indicadores con mayor peso en este índice son la pobreza monetaria y extrema, la tasa de analfabetismo y la mortalidad infantil. Como se muestra en el Gráfico 9, el índice de exclusión social en Santa Marta se ubica por encima del promedio de las 23 ciudades principales e intermedias, ocupando el cuarto lugar con peor desempeño después de Quibdó, Riohacha y Florencia.

Con esta primera mirada a la pobreza de Santa Marta, es evidente que aún hay muchos retos por superar. Los indicadores muestran una pobreza menos ligada al acceso a los servicios, pero con mayores desafíos en materia de calidad. A pesar de los avances, estos no han sido suficientes para eliminar el rezago con respecto a

\section{GRÁFICO 9}

23 ciudades principales e intermedias de Colombia: Índice de exclusión social, 2016

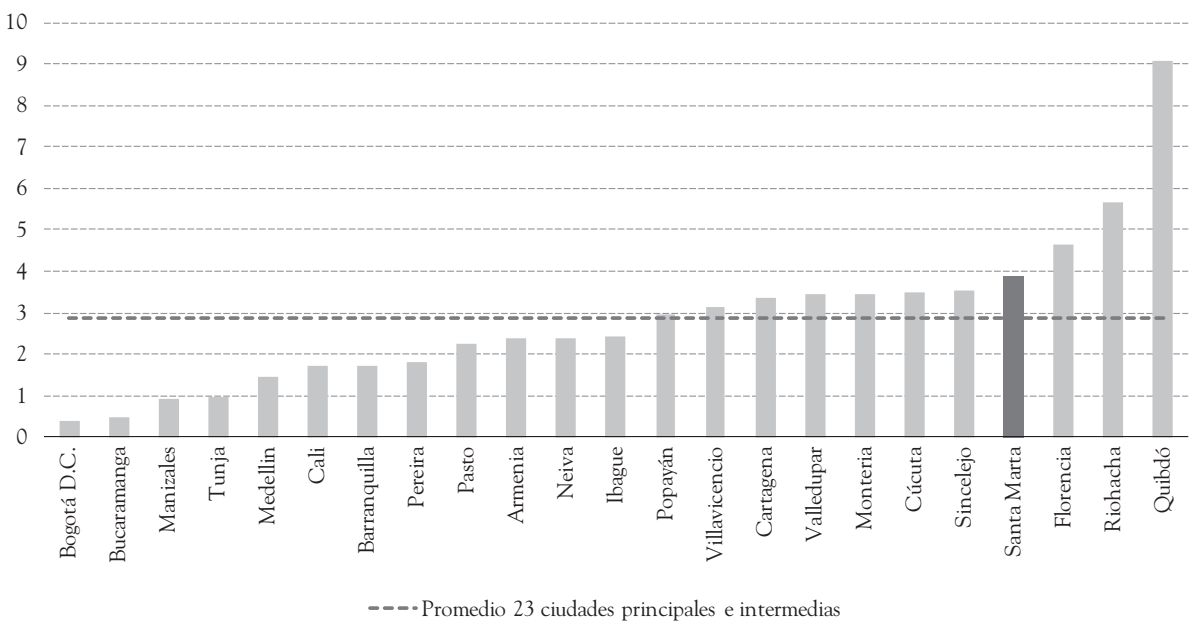

Fuentes: Elaboración propia con base en Ayala y Meisel (2016). 
las otras ciudades. Por el contrario, este parece estar creciendo. Si se quiere una vez más revertir esta tendencia, es esencial conocer en detalle la situación de los más pobres, quiénes son, qué los caracteriza y cuáles son sus principales necesidades. Responder a estas preguntas es un objetivo de este documento.

\section{B. Dimensión espacial}

El análisis espacial es parte esencial del diseño y ejecución de políticas destinadas a reducir la pobreza. El uso de mapas facilita la identificación de áreas donde se concentran los más pobres, permitiendo así una mejor focalización y eficiencia en el gasto. Por otro lado, es también una importante herramienta en el planeamiento urbano de las ciudades, por ejemplo, en la búsqueda de una integración de sectores pobres aislados con los centros de producción, institucionales y de recreación. Finalmente, combinando los mapas de pobreza con otro tipo de información espacial, se pueden identificar posibles determinantes de la pobreza, como el origen étnico, el acceso a servicios públicos o la geografía (Bedi, et al., 2007).

Algunos trabajos han analizado la dimensión espacial de la pobreza para ciudades colombianas. Aguilera y Meisel (2009), Romero (2007), Pérez y Salazar (2007), y Ayala y Meisel (2017) lo hacen para Cartagena. Usando mapas, todos coinciden en la existencia de una relación estrecha entre la pobreza y el origen étnico y el logro educativo de la población. Cepeda (2011) encuentra para Barranquilla una gran concentración de la pobreza en el sur de la ciudad, donde coinciden también una mayor exposición al riesgo por desastres naturales, deficiente prestación de servicios públicos, baja escolaridad y mayor porcentaje de afrocolombianos. Hosie, et al. (2018) realizaron un análisis de la situación social del barrio Pescaito en Santa Marta, incorporando en los planos las diferentes dimensiones de la vida de sus habitantes. Más allá de ese trabajo, no hay estudios que abordan el tema; aquellos que lo hacen no incluyen los mapas como parte esencial del análisis.

\section{Ordenamiento territorial de Santa Marta}

El Distrito de Santa Marta está conformado por un mar territorial, un área montañosa, cuerpos de agua interiores, una zona costera y continental y un suelo no consolidado constituido por la zona de bajamar, el subsuelo y el espacio aéreo asociado. Tiene un área de 239.335 hectáreas, que se extienden por el norte desde 
la desembocadura de la quebrada El Doctor, bordeando todo el litoral, hasta la desembocadura del río Palomino y, por el sur, hasta el límite con los municipios de Aracataca y Ciénaga (Concejo del Distrito Turístico, Cultural e Histórico de Santa Marta, 2000).

El Plan de Ordenamiento Territorial de Santa Marta "Jate Matuna (2000 2009)" plantea una división del territorio de nueve comunas en la zona urbana, y cuatro corregimientos y un resguardo indígena en la rural. Esta división fue modificada con el Proyecto de Localidades aprobado en 2015, en el cual desaparecieron las nueve comunas y se agruparon estas en tres localidades. El Mapa 1 ilustra esta nueva división de la zona urbana.

Además del área urbana de las localidades, cada una de ellas cuenta con un área rural y un área de expansión urbana. La localidad número 1, llamada Cultural-San Pedro Alejandrino, comprende también los corregimientos de Bonda y Guachaca, y un resguardo indígena en la zona rural. Por su parte, la localidad 2, o Histórica-Rodrigo de Bastidas, cuyos límites con la 1 se encuentran marcados por el cauce del río Manzanares, incluye también el corregimiento de Taganga. Finalmente, la localidad 3, conocida como Turística-Perla del Caribe, que limita al sur con el municipio de Ciénaga, incluye también dentro de su territorio al corregimiento de Minca (Concejo del Distrito Turístico, Cultural e Histórico de Santa Marta, 2000).

\section{Mapas de pobreza}

El análisis de la distribución espacial de la población más pobre se realiza usando la base de datos del Sistema de Identificación de Potenciales Beneficiarios de Programas Sociales (sISBEN). Este sistema se ha convertido en el principal instrumento de focalización individual en Colombia y es ampliamente usado como criterio principal o complementario en diversos programas sociales e instituciones del país. Más específicamente, los datos a usar hacen parte de la tercera versión de la misma, que inició su operación en 2011 y está vigente en la actualidad. La encuesta fuente de los datos contiene una serie de preguntas en los temas de salud, educación, vivienda y vulnerabilidad (Flórez, et al., 2008).

La base está conformada por 236.196 personas, de las cuales el $88 \%$ vive en la cabecera, $51 \%$ son mujeres, y $28 \%$ son niños menores de 12 años. Cabe señalar que el SISBEN no representa el total de la población de Santa Marta, sino solo a los más pobres. A pesar de lo anterior, si se comparan los datos del sIsBEN con el 


\section{MAPA 1}

Santa Marta: Localidades (zona urbana) definidas por el Proyecto de Localidades de 2015

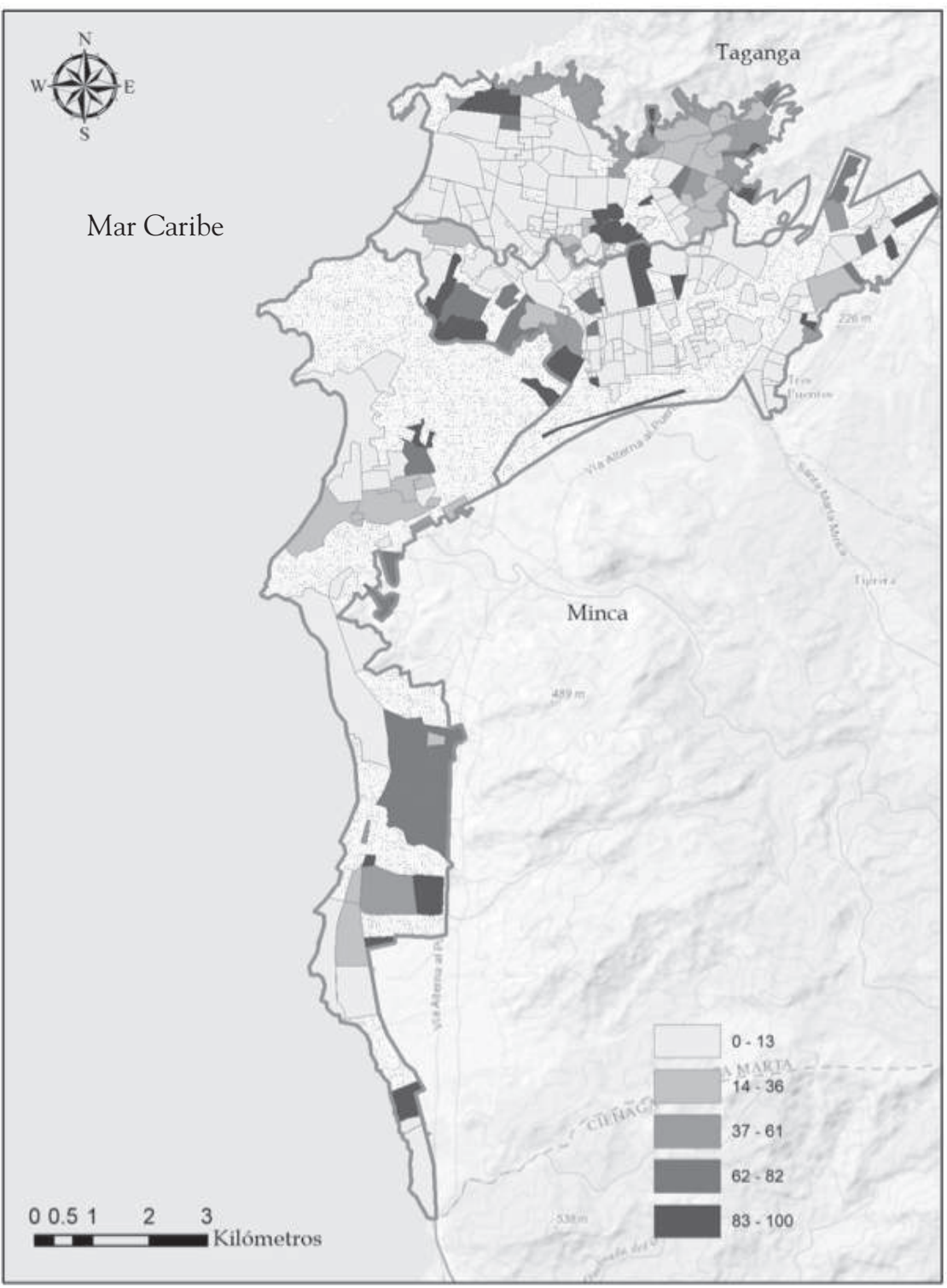

Fuentes: Elaboración propia con base en datos de la Secretaría de Planeación Distrital de Santa Marta. 
universo de la población, los habitantes en la primera resultan ser una proporción no depreciable. Según las proyecciones de población del DANE, en 2011 estos representaban 55\% de la población total de Santa Marta.

A pesar de que la información espacial por barrio solo está disponible hasta 2011, con los datos actualizados a diciembre de 2017 es posible conocer algunos indicadores para el agregado de la población. Según el índice de NBI para el total de personas en el SISBEN a 2017, 83\% viven en situación de pobreza. El Cuadro 2 muestra en mayor detalle su situación tomando como referencia las principales características de los jefes de hogar clasificados como pobres.

CUADRO 2

Santa Marta: Características de los jefes de hogar en condición de pobreza, 2017

(porcentajes)

\begin{tabular}{|c|c|c|c|c|c|}
\hline & \multirow{2}{*}{\multicolumn{2}{|c|}{ Cabecera }} & \multirow{2}{*}{\multicolumn{2}{|c|}{ Resto }} \\
\hline & & & & & \\
\hline & & Hombre & Mujer & Hombre & Mujer \\
\hline \multirow{3}{*}{ Nivel educativo } & Ninguno, Primaria & 52,1 & 47,6 & 68,5 & 57,8 \\
\hline & Secundaria & 47,3 & 50,8 & 29,3 & 41,3 \\
\hline & Técnico, Universidad, Posgrado & 0,6 & 1,6 & 2,2 & 0,9 \\
\hline \multirow{6}{*}{ Actividad } & Sin actividad & 25,4 & 19,4 & 21,7 & 16,5 \\
\hline & Trabajando & 58,0 & 16,8 & 66,8 & 17,8 \\
\hline & Buscando trabajo & 10,7 & 4,1 & 7,1 & 3,0 \\
\hline & Estudiando & 2,4 & 1,0 & 2,2 & 2,6 \\
\hline & Oficios del hogar & 3,0 & 58,4 & 1,6 & 60,0 \\
\hline & Rentista, Jubilado, Pensionado & 0,6 & 0,3 & 0,5 & 0,0 \\
\hline Régimen de salud & Contributivo & 7,1 & 7,9 & 7,1 & 6,5 \\
\hline
\end{tabular}

Fuentes: Elaboración propia con base en datos del SISBEN.

En primer lugar, el bajo logro educativo es un aspecto recurrente en todos los casos, trátese de la zona urbana o rural, o de un jefe de hogar hombre o mujer. Más del 90\% cuenta con educación secundaria o menos; en educación superior las cifras difícilmente alcanzan el $2 \%$. Por otro lado, en cuanto a las actividades que realizan, es evidente una enorme carga de las mujeres en los oficios del hogar 
y una baja participación de ellas en el mercado laboral. Los hombres, por su parte, se encuentran en su mayoría trabajando. Por ejemplo, en la zona rural el $60 \%$ de las mujeres se dedican a los oficios del hogar, mientras que para el caso de los hombres esta cifra es de solo 1,6\%. Este es un fenómeno que revela una de las grandes barreras que enfrentan las mujeres a la hora de acceder a un trabajo con estabilidad y perspectivas de crecimiento.

La última característica que presenta el cuadro hace referencia al porcentaje de personas afiliadas al régimen contributivo de salud. Si comparamos la afiliación a este régimen con el porcentaje de personas que trabajan, la primera resulta mucho menor, lo cual es un primer indicio sobre el problema de informalidad que se vive en la ciudad.

Habiendo conocido sus principales características, el siguiente paso es saber en qué lugares de Santa Marta se concentran estas personas. El Mapa 2 presenta la distribución espacial de la pobreza en los barrios de la ciudad. La variable usada en este caso es el porcentaje de personas con NBI. Al no contar con información para el universo de la población desagregada por barrio, esta medida se calcula a partir del número de personas en el SISBEN en cada vecindario. En el caso de que no existan personas en el SISBEN, la incidencia de la pobreza en ese barrio se asume como 0 . Esta medida nos permite conocer los barrios con mayores necesidades, controlando de alguna forma por su tamaño demográfico.

A manera de complemento, el Cuadro 3 presenta los barrios con mayor número de pobres, una medida que no necesariamente coincide con una elevada incidencia de pobreza. Al decidir sobre la implementación de políticas es importante considerar ambos indicadores. De hecho, se podría decir que aquellos barrios con la situación más alarmante son los que, además de tener una incidencia alta, alojan el mayor número de pobres de la ciudad.

Con base en las medidas de incidencia y número de pobres, los barrios con una mayor urgencia de atención en la Localidad 1 son: María Cecilia, 11 de Noviembre y Timayui I y II; en la Localidad 2: los Fundadores, San Jorge y el Cerro las Tres Cruces; y en la Localidad 3: La Paz, Cristo Rey y La Quemada. En esta última localidad, a pesar de que el barrio Gaira concentra un gran número de pobres, la proporción de estos con respecto al total de la población no alcanza a estar en los rangos más altos, razón por la cual no se considera que se halla en situación crítica.

$\mathrm{Si}$, además, se evalúa el comportamiento de cada una de las necesidades al interior de este indicador, se encuentra que la necesidad más recurrente es la falta de acceso a los servicios públicos de acueducto y alcantarillado. En el caso particu- 


\section{MAPA 2}

Santa Marta: Porcentaje de personas con NBI por barrio, 2011

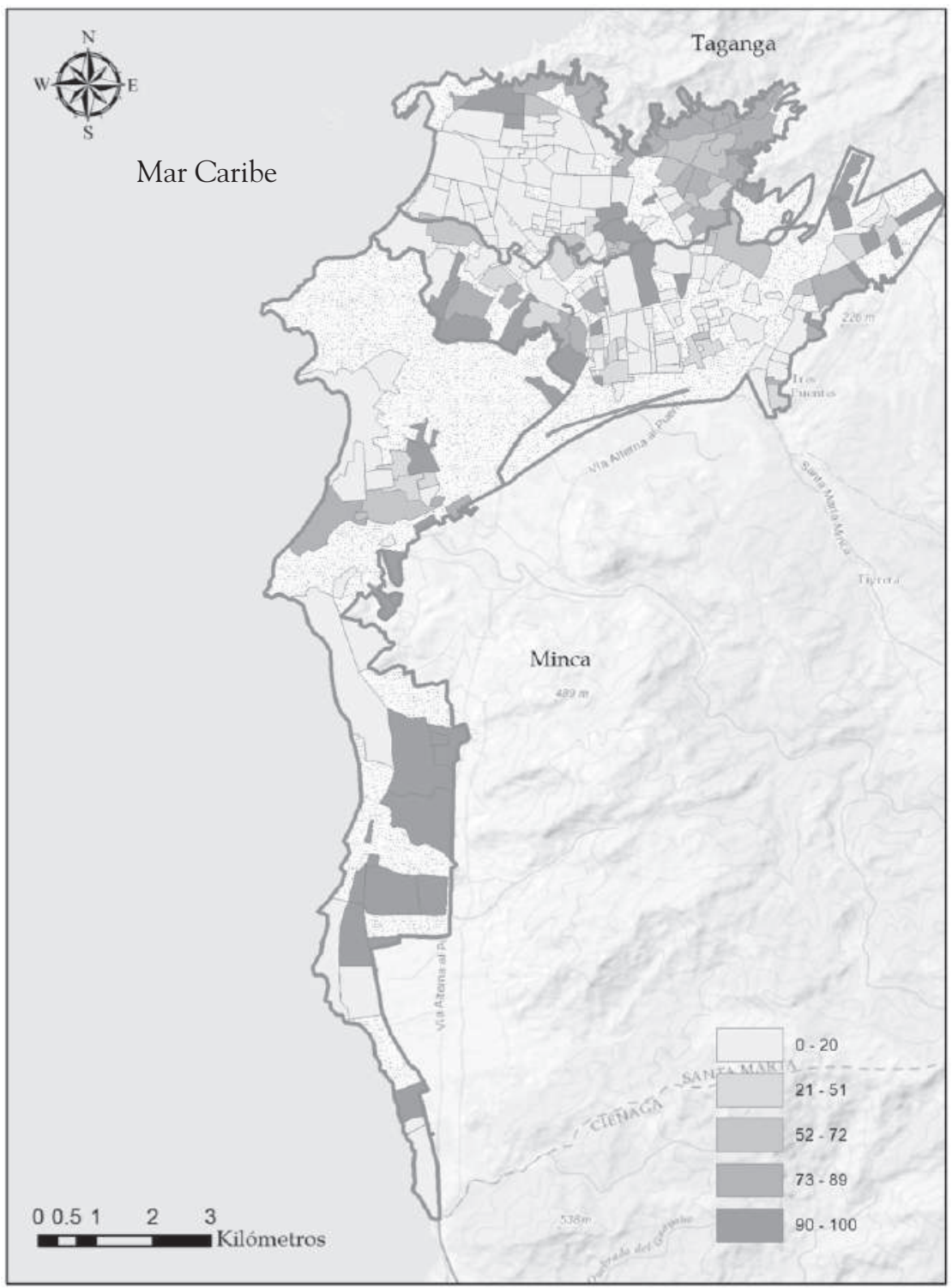

Fuentes: Elaboración propia con base en datos de la Secretaría de Planeación Distrital de Santa Marta y del SISBEN. 


\section{CUADRO 3}

Santa Marta: Barrios con mayor número de personas en condición de pobreza, 2011

\begin{tabular}{|c|c|c|}
\hline Barrio & Número de personas con NBI & Porcentaje del total en SISBEN \\
\hline \multicolumn{3}{|c|}{ Localidad 1} \\
\hline Maria Cecilia & 9.418 & 99,6 \\
\hline 11 de Noviembre & 5.995 & 76,0 \\
\hline Timayui I y II & 5.027 & 91,6 \\
\hline Maria Eugenia & 3.650 & 86,3 \\
\hline San Jose del Pando & 3.571 & 93,0 \\
\hline Santa Ana & 3.025 & 99,9 \\
\hline Colinas del Pando & 2.409 & 91,5 \\
\hline 20 de Octubre & 2.369 & 97,3 \\
\hline Misael Pastrana & 2.300 & 96,8 \\
\hline San Pablo & 2.219 & 97,6 \\
\hline \multicolumn{3}{|c|}{ Localidad 2} \\
\hline Los Fundadores & 5.129 & 82,3 \\
\hline San Jorge & 4.914 & 88,7 \\
\hline Cerro Las Tres Cruces & 4.122 & 97,7 \\
\hline Luis R Calvo & 4.028 & 88,4 \\
\hline Pantano & 3.591 & 83,6 \\
\hline San Fernando & 3.556 & 76,8 \\
\hline Divino niño & 2.892 & 84,4 \\
\hline Nacho Vives & 2.733 & 83,1 \\
\hline Ondas del Caribe & 2.458 & 84,4 \\
\hline Juan XXIII & 2.428 & 88,1 \\
\hline Tayrona parte alta & 2.423 & 77,7 \\
\hline \multicolumn{3}{|c|}{ Localidad 3} \\
\hline Gaira & 9.137 & 64,1 \\
\hline $\mathrm{La} \mathrm{Paz}$ & 8216 & 99,6 \\
\hline Cristo Rey & 3.239 & 99,8 \\
\hline La Quemada & 2.650 & 92,9 \\
\hline \multicolumn{3}{|c|}{ Zona rural } \\
\hline Minca & 3.508 & 99,9 \\
\hline Taganga & 4.153 & 100,0 \\
\hline Guachaca & 13.387 & 99,9 \\
\hline
\end{tabular}

Fuentes: Elaboración propia con base en datos del SISBEN. 
lar del barrio Las Tres Cruces, uno de los mayores problemas es la presencia de viviendas con paredes y pisos construidos con materiales inadecuados.

Finalmente, el Cuadro 3 también incluye también los corregimientos de la zona rural de Santa Marta que no se presentan en el mapa. Como era de esperarse, por la menor provisión de servicios básicos, la incidencia de la pobreza en estas zonas es más alta. El corregimiento de Guachaca, zona rural de la Localidad 1, cuenta con 13.387 personas en condición de pobreza, correspondiente al 99\% de la población en el SISBEN. A esta le siguen los corregimientos de Taganga y Minca, con cerca de 4.000 y 3.000 pobres, respectivamente, y con una alta incidencia que, en el caso de la primera, abarca a la totalidad de la población en el SISBEN.

\section{Empleo}

Según el DANE, en el último trimestre de 2017 el desempleo en Santa Marta alcanzó una cifra de 7\%, ubicándose como la segunda ciudad con menor desempleo dentro de las 23 ciudades principales e intermedias del país. A pesar de la mayor generación de empleo, los alcances de esta reducida cifra en términos de bienestar de la población podrían estar siendo limitados por el gran tamaño del sector informal en la ciudad. En particular, para este mismo período, aproximadamente 316.000 personas, equivalentes a $63 \%$ de la población, se encontraban empleadas en el sector informal. Con esta cifra, Santa Marta se ubica por encima del promedio nacional; entre las 23 ciudades principales e intermedias, ocupa la cuarta posición con mayor incidencia de este fenómeno (Gráfico 10). Por otro lado, la ciudad cuenta con una baja participación laboral. En este mismo trimestre la tasa global de participación fue de 59\%, siendo la cuarta más baja entre las 23 ciudades.

La información del SISBEN permite tener una visión adicional del problema de informalidad, examinando el tipo de afiliación al régimen de salud. Esto es, considerando como informales a las personas que se encuentran trabajando, pero que no cuentan con afiliación al régimen contributivo o especial de salud. Visto así, en 2011 el 87\% de la población en el SISBEN en Santa Marta que trabajaba lo hacía en el sector informal. El Mapa 3 presenta este indicador desagregado para los barrios de la ciudad. Además, el Cuadro 4 muestra la incidencia de este fenómeno en los corregimientos de la zona rural.

Usando el mismo criterio empleado para el caso de la pobreza, los barrios que requieren de una mayor atención en materia de informalidad serían, en la Localidad 1: María Cecilia, 11 de Noviembre y Timayui i y II; en la Localidad 2: Los 


\section{GRÁFICO 10}

23 ciudades principales e intermedias de Colombia: tasa de informalidad, octubre - diciembre de 2017

\section{(porcentajes)}

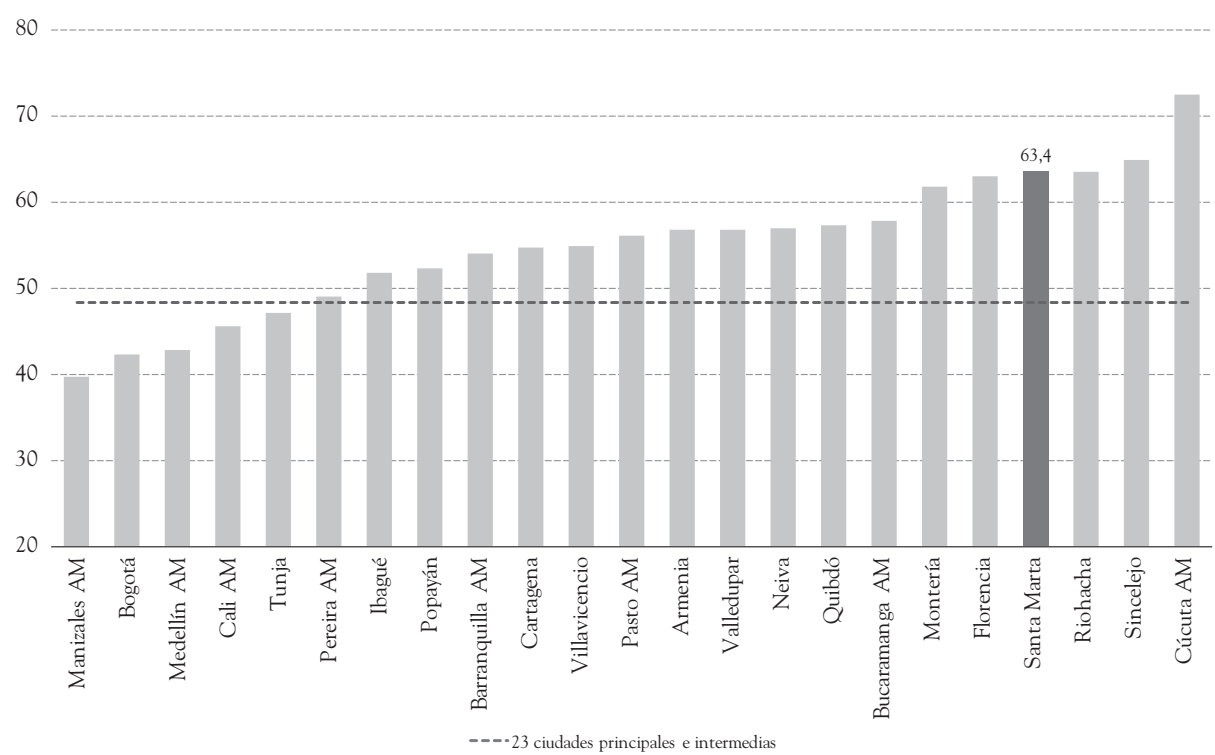

Notas: 1) La tasa de informalidad en este caso se cálcula como el porcentaje de ocupados en empresas de hasta cinco trabajadores. 2) AM: Área Metropolitana.

Fuentes: Elaboración propia con base en datos de la GEIH del DANE.

Fundadores, San Jorge y el Cerro Las Tres Cruces; y en la 3: La Paz, La Quemada y Cristo Rey. Finalmente, en las zonas rurales, los corregimientos de Taganga y Guachaca son los que, además de contar con una incidencia alta, tienen el mayor número de empleados informales.

Salvo algunas excepciones, una elevada informalidad coincide con alta pobreza en la mayoría de los barrios considerados. Para explorar un poco la relación entre estas dos variables, el Gráfico 11 presenta las tasas de informalidad y pobreza por NBI para cada uno de los barrios en la base del SISBEN de Santa Marta. Con base en esta ilustración, es clara la existencia de una relación positiva entre estas dos variables. En particular, el coeficiente de correlación entre ellas alcanza un valor de 0,65 y resulta estadísticamente significativo. 
MAPA 3

Santa Marta:

Porcentaje de personas con empleos informales por barrio, 2011

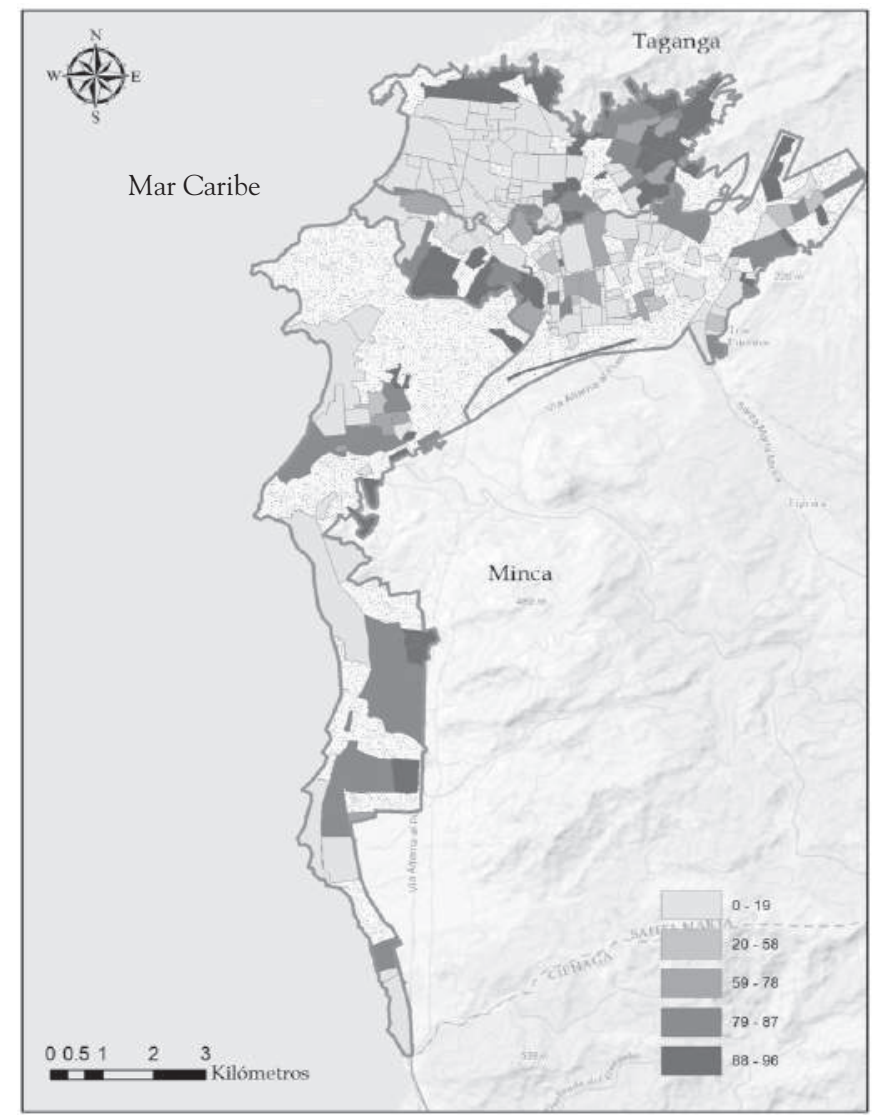

Fuentes: Elaboración propia con base en datos de la Secretaría de Planeación Distrital de Santa Marta y del SISBEN.

\section{CUADRO 4}

Santa Marta: Informalidad en los corregimientos de la zona rural, 2011

\begin{tabular}{|l|c|c|}
\hline \multicolumn{1}{|c|}{ Corregimiento } & $\begin{array}{c}\text { Número de empleados } \\
\text { informales }\end{array}$ & $\begin{array}{c}\text { Porcentaje del total } \\
\text { de ocupados }\end{array}$ \\
\hline Minca & 926 & 93,8 \\
\hline Taganga & 1.016 & 94,0 \\
\hline Guachaca & 3.061 & 93,9 \\
\hline
\end{tabular}

Fuentes: Elaboración propia con base en datos del SISBEN. 


\section{GRÁFICO 11}

Santa Marta: Informalidad y pobreza en los barrios, 2011

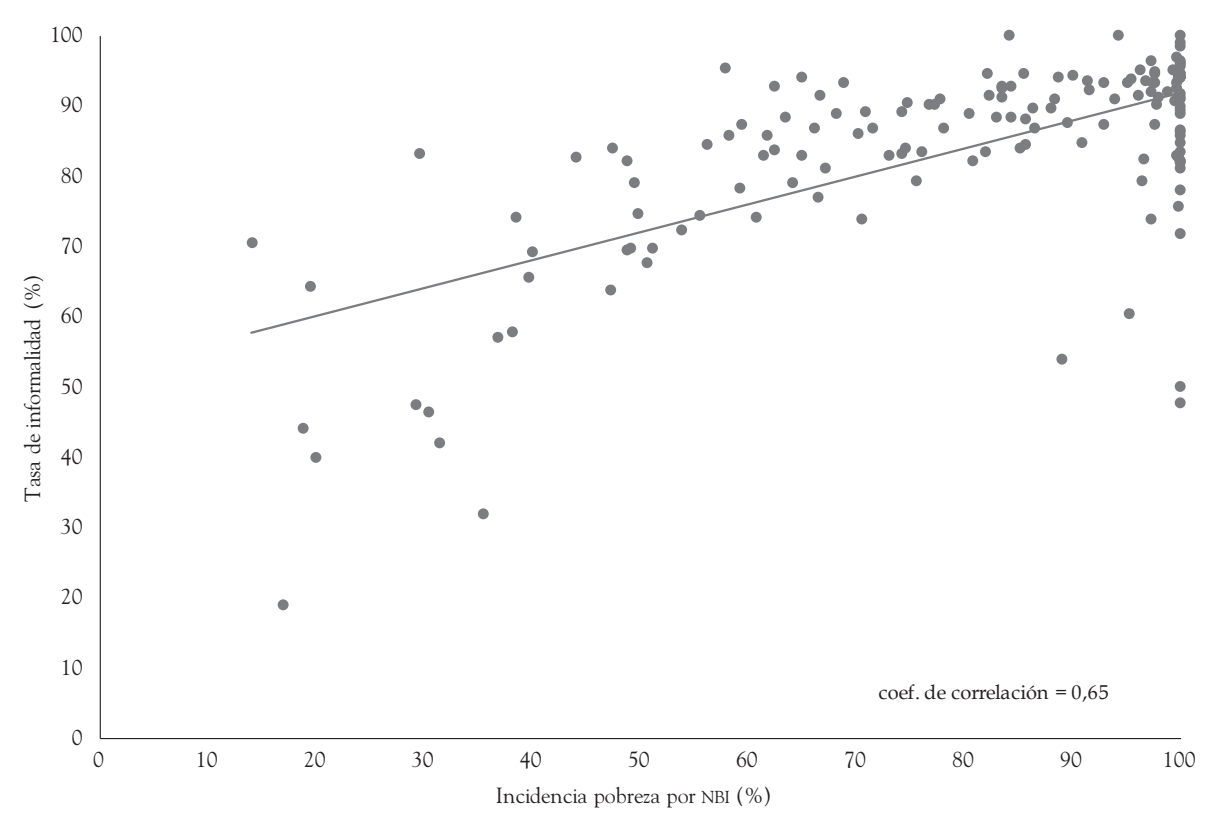

Fuentes: Elaboración propia con base en datos del SISBEN.

Varios factores explican este hallazgo. Por un lado, los reducidos salarios, que hacen de las actividades informales una simple estrategia de supervivencia con poca estabilidad y perspectivas de crecimiento. Además, la carencia de protección social, como el acceso restringido a seguros de salud y accidentes de trabajo, aumenta la exposición a riesgos, reduciendo de igual manera el bienestar de las personas (Freije, 2002). Por último y un poco menos directo, una gran proporción de trabajadores informales podría reducir el flujo de recursos en los sistemas pensionales y de salud y, por lo tanto, arriesgar su sostenibilidad.

Pero más allá de estos factores, es indispensable examinar aquellos que impulsan la aparición de estos empleos en la ciudad. El bajo logro educativo es uno de ellos, tal vez el más importante para el caso de Santa Marta. Para evaluar lo anterior, el Gráfico 12 ilustra la relación de esta última variable y la tasa de informalidad en los barrios en el SISBEN de Santa Marta. Como se puede observar, en el agregado de los barrios más pobres, efectivamente existe una relación positiva entre la tasa de informalidad y el bajo logro educativo de la población. 


\section{GRÁFICO 12}

Santa Marta: Informalidad y bajo logro educativo en los barrios, 2011

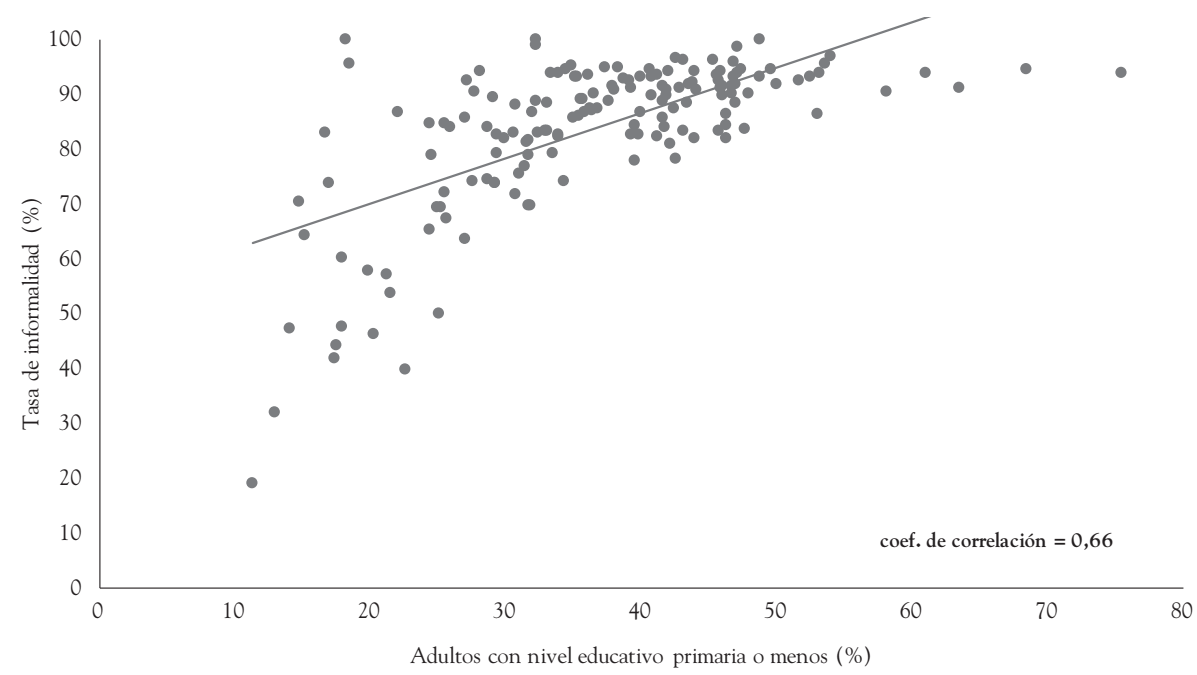

Fuentes: Elaboración propia con base en datos del SISBEN.

Con esto, la educación se convierte en un tema clave, teniendo en cuenta que la economía de Santa Marta gira en torno a actividades terciarias, un sector intensivo en capital humano. Para acceder a las actividades formales y de mayor productividad en este sector, es necesario contar con un avanzado nivel educativo. Cuando esto no es una realidad, el sector se convierte en una oportunidad para desempeñar actividades de baja productividad y con bajos requerimientos de capital físico y tecnología (Weller, 2004).

El Cuadro 5 confirma esta última idea. Allí se compara para 2017 el grado de informalidad de las distintas actividades económicas de Santa Marta contra el promedio de años de educación de los ocupados en cada una. El sector de comercio, hoteles y restaurantes, que en ese año representó el 34\% del empleo total de la ciudad, tiene una tasa de informalidad del 70\%, la segunda más alta después del sector de la construcción. En este mismo sector de comercio, hoteles y restaurantes, el promedio de años de educación es de solo 9,7, superior únicamente al nivel educativo en los sectores de construcción, y agricultura, pesca, ganadería, caza y silvicultura. A pesar de hacer parte de un sector que tiene el potencial de abarcar actividades altamente productivas, en Santa Marta, al igual que en otras ciudades colombianas, estas actividades representan una parte importante de la informalidad. 


\section{CUADRO 5 \\ Santa Marta: Informalidad y logro educativo por ramas de actividad económica, 2017}

\begin{tabular}{|l|c|c|}
\hline \multicolumn{1}{|c|}{ Actividad } & $\begin{array}{c}\text { Tasa de } \\
\text { Informalidad }\end{array}$ & $\begin{array}{c}\text { Promedio años } \\
\text { de educación }\end{array}$ \\
\hline Construcción & 78,2 & 8,3 \\
\hline Comercio, hoteles y restaurantes & 69,8 & 9,7 \\
\hline Transporte, almacenamiento y comunicaciones & 65,9 & 9,8 \\
\hline Industria manufacturera & 64,8 & 9,6 \\
\hline Actividades inmobiliarias & 56,4 & 10,7 \\
\hline Agricultura, pesca, ganadería, caza y silvicultura & 52,9 & 8,6 \\
\hline Servicios comunales, sociales y personales & 39,9 & 11,9 \\
\hline Intermediación financiera & 20,0 & 12,7 \\
\hline Explotación de minas y canteras & 5,1 & 11,5 \\
\hline Electricidad, gas y agua & 4,6 & 11,5 \\
\hline
\end{tabular}

Nota: La tasa de informalidad está expresada en porcentajes.

Fuente: Fuente de Información Laboral en Colombia (FILCO).

Hasta el momento solo se han considerado factores asociados a la oferta laboral. No obstante, existen aspectos de la demanda que podrían influir en la aparición de empleos informales. Uno de ellos es la distribución espacial de los empleos formales en Santa Marta. Los altos costos de transporte y la carencia de medios de comunicación en algunos sectores de la ciudad, podría estar limitando la movilización de trabajadores y, en consecuencia, su preferencia por trabajos informales de más fácil acceso (Ruggeri, 2005). En el caso particular de Santa Marta, algunos de los barrios en grave situación de informalidad y pobreza, como el Cerro Las Tres Cruces y San Jorge, también cuentan con limitaciones de acceso a los grandes centros de producción, que concentran la actividad económica de la ciudad. Algunas acciones que contribuirían a la eliminación de este tipo de barreras son el incremento de las rutas de acceso y el mejoramiento de la planificación urbana.

Las diferencias en las tasas de desempleo de hombres y mujeres en la ciudad es otro tema que debe ser evaluado y discutido. En el último trimestre de 2017, mientras que la tasa de desempleo masculino en Santa Marta fue de 3,9\%, la 
femenina alcanzó 11,1\% (Gráfico 13), una brecha de aproximadamente 7 pp. Por su parte, en el agregado nacional esta misma brecha fue de solo $2 \mathrm{pp}$. A pesar de ser un fenómeno común de la pobreza en Colombia, la brecha en Santa Marta da muestra del rezago de la ciudad en este aspecto, el cual no parece haber experimentado importantes progresos en los últimos años.

\section{Cobertura de acueducto y alcantarillado}

El acceso a servicios de agua potable y saneamiento básico es un tema crucial en la superación de la pobreza. Invertir en el mejoramiento de estos servicios puede traer grandes beneficios al bienestar de las personas, especialmente en salud y educación. Según la Organización Mundial de la Salud (WHO, por sus siglas en inglés), $26 \%$ de las muertes de niños y $25 \%$ de los efectos de enfermedades en niños menores de 5 años se pueden evitar con la reducción de riesgos ambientales, como el consumo de aguas no tratadas, y saneamiento e higiene inadecuados (World Health Organization - wHO, 2017).

\section{GRÁFICO 13}

Santa Marta: Tasa de desempleo de hombres y mujeres, 2007 - 2017 (trimestre móvil)

(porcentajes)

$$
25
$$

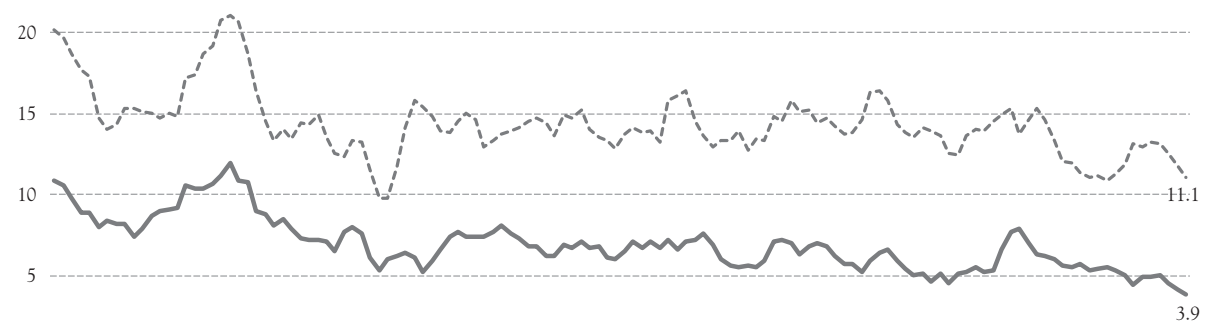

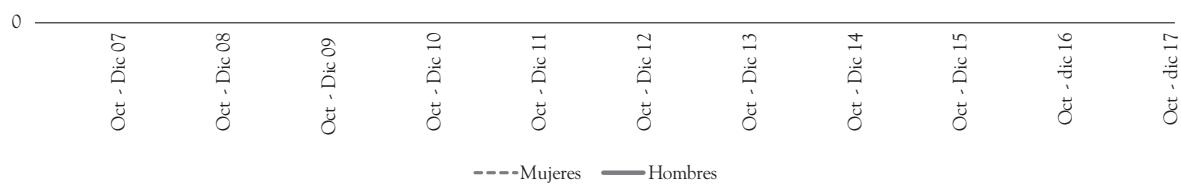

Fuentes: Elaboración propia con base en datos de la GEIH del DANE. 
El Gráfico 14 muestra el grado de progreso en cobertura de servicios públicos en Santa Marta y las 23 ciudades principales e intermedias, calculado por el Departamento Nacional de Planeación para 2016. Este indicador es parte de la medida de desempeño municipal que construye el DNP e incluye en sus dimensiones la cobertura eléctrica rural, la cobertura en servicios de internet y la cobertura de acueducto y alcantarillado. Como se puede observar, con un puntaje de 44 Santa Marta ocupa el último lugar en materia de cobertura de servicios. En particular, las dos dimensiones con menor desempeño son los servicios de acueducto y alcantarillado. Cabe aclarar que el cálculo de este índice se hace a partir de los datos auto reportados por las empresas prestadoras de servicios públicos.

Debido a las limitaciones de la medida anterior, el análisis se complementa con información proveniente de las encuestas del sisben. En Santa Marta, en $2017,51 \%$ y $62 \%$ de las personas en el SISBEN no contaban con servicios de alcantarillado y acueducto, respectivamente. Los Anexos 1 y 2 muestran estas cifras desagregadas para los barrios de la ciudad. Además, los Anexos 3 y 4 presentan la información para los corregimientos de la zona rural.

\section{GRÁFICO 14}

23 ciudades principales e intermedias de Colombia:

Puntaje en cobertura de servicios públicos, 2016

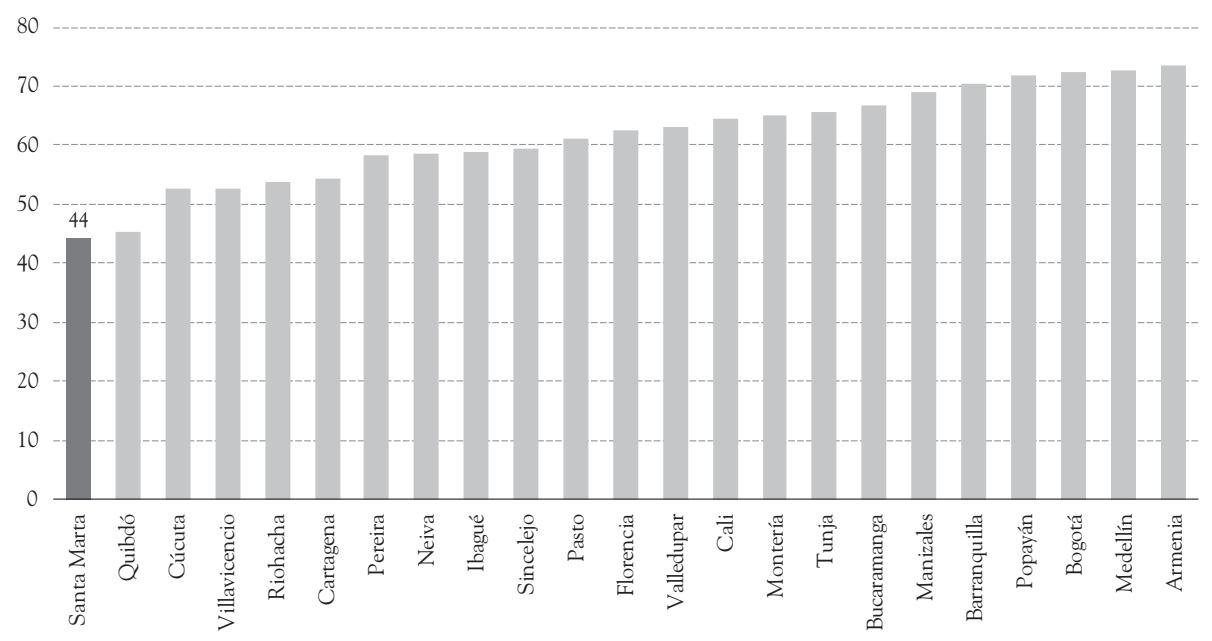

Fuentes: Elaboración propia con base en la Medición del Desempeño Municipal del DNP. 
Los barrios con mayores necesidades en materia de acueducto en la Localidad 1 son Maria Cecilia y Santa Ana; en la Localidad 2, el Cerro Las Tres Cruces; y en la Localidad 3, La Quemada. En cuanto a alcantarillado, son Maria Cecilia y Santa Ana en la Localidad 1 y La Paz y Cristo Rey en la Localidad 3. En cuanto a las zonas rurales, los tres corregimientos considerados, Minca, Taganga y Guachaca, presentan una alta incidencia de estos problemas.

Al no contar con acceso al servicio de acueducto, los habitantes de estos barrios deben acudir a otras fuentes de abastecimiento, como agua embotellada, carrotanques, pozos, ríos o quebradas. Algunos, especialmente quienes viven en asentamientos informales, terminan conectándose fraudulentamente a las redes de aducción y conducción del sistema de acueducto (Gaviria, 2017).

Por su parte, los barrios que sí cuentan con el servicio deben enfrentarse en cierta medida a otro tipo de problemas, como las frecuentes interrupciones del servicio. Para el caso específico de Santa Marta, en 2016 el promedio de continuidad del servicio de acueducto fue de 15,76 horas por día (Superintendencia de Servicios Públicos Domiciliarios - Superservicios, 2017).

Pero, más allá del acceso a los servicios, es importante garantizar su calidad. En cuanto al servicio de acueducto, el agua no apta para el consumo humano puede generar enfermedades infecciosas y parasitarias, especialmente en niños menores de 5 años (Gaviria, 2017). Según los resultados de vigilancia de la calidad de agua en la red de distribución, en algunos meses de 2015 y 2016 se presentaron deficiencias en la calidad del agua en Santa Marta. Más específicamente, en los meses de febrero, marzo, mayo, agosto y septiembre de 2015 y los meses de abril y octubre de 2016, el índice de riesgo de calidad del agua, en una escala de $0 \%$ a $100 \%$, estuvo por encima de $5 \%$, valor máximo permitido para el consumo humano (Superservicios, 2017).

El sistema de alcantarillado tiene también importantes deficiencias. Principalmente en temporadas de lluvias, son recurrentes las obstrucciones en tramos de tuberías, lo que ocasiona rebosamientos de aguas negras en zonas como la Carrera 1, aledaña al puerto y los barrios Pescaito, Bellavista y El Rodadero. Las inundaciones y los malos olores terminan afectando tanto la calidad de vida de la población como la actividad turística del sector (Ibid., 2017).

La Alcaldía de Santa Marta ha emprendido varias acciones con relación a este tema. Una fue el cambio de la empresa responsable de la provisión de estos servicios en la ciudad. Tras la terminación de un contrato de 27 años con la empresa metroagua, en abril de 2017, la Empresa de Servicios Públicos de Santa Marta 
(ESSMAR) y su aliado estratégico VEOLIA asumieron la operación por un año de los sistemas de acueducto y alcantarillado. No obstante, es difícil lograr una mejora inmediata, ya que la infraestructura y las fuentes de abastecimiento continúan siendo las mismas.

\section{Riesgos ambientales}

La llegada masiva de personas a las ciudades, sin un progreso similar en materia de infraestructura y planeamiento urbano, ha resultado en la conformación de asentamientos informales. En el caso de los desplazados del conflicto armado, al llegar a las ciudades completamente despojados de sus bienes y recursos, la autoconstrucción de casas se convierte en el único medio de consecución de vivienda a bajo costo (Sanghee, 2017). Este es un fenómeno recurrente en las ciudades de países en desarrollo, donde los más pobres terminan habitando viviendas informales, vulnerables a los desastres naturales y con deficiencias en la provisión de servicios públicos (Fay y Wellenstein, 2005).

Además de estar ubicadas en áreas vulnerables, las amenazas del calentamiento global (aumento del nivel del mar, ciclones tropicales fuertes y tormentas intensas) incrementan los riesgos de pérdida en estas viviendas. Más aun, si los asentamientos se ubican en zonas costeras, este tipo de amenazas podrían terminar destruyendo por completo infraestructuras y obligando al desplazamiento de poblaciones enteras (Instituto de Investigaciones Marinas y Costeras - INVEMAR, 2016).

En Santa Marta, según INVEMAR (2016), las principales amenazas son el mar de leva, los sismos, la erosión costera, los vendavales o tormentas, y las inundaciones. Este último es quizás el fenómeno más recurrente. Las fuertes tormentas y en algunos casos los eventos extremos, llevan al desbordamiento de ríos de gran torrencialidad en la ciudad, como el Manzanares y el Gaira. El mar de leva, por su parte, produce inundaciones en los sectores aledaños a las playas y, en muchos casos, termina ocasionando averías en construcciones como muelles y viviendas. En el Mapa 4 se muestran los puntos de la ciudad que se encuentran directamente expuestos a estas amenazas.

La oficina de Gestión del Riesgo afirma que algunos de los barrios más afectados por inundaciones en 2017 fueron, en la Localidad 1: Maria Eugenia, Pastrana, Las Acacias, Colinas del Pando, Santa Ana y Las Américas; en la Localidad 2: Pescaito, el Centro Histórico, Las Malvinas, Bastidas, Nacho Vives, Chimila 1 y 2 , Fundadores y Galicia. 


\section{MAPA 4}

Santa Marta: Zonas amenazadas por el cambio climático

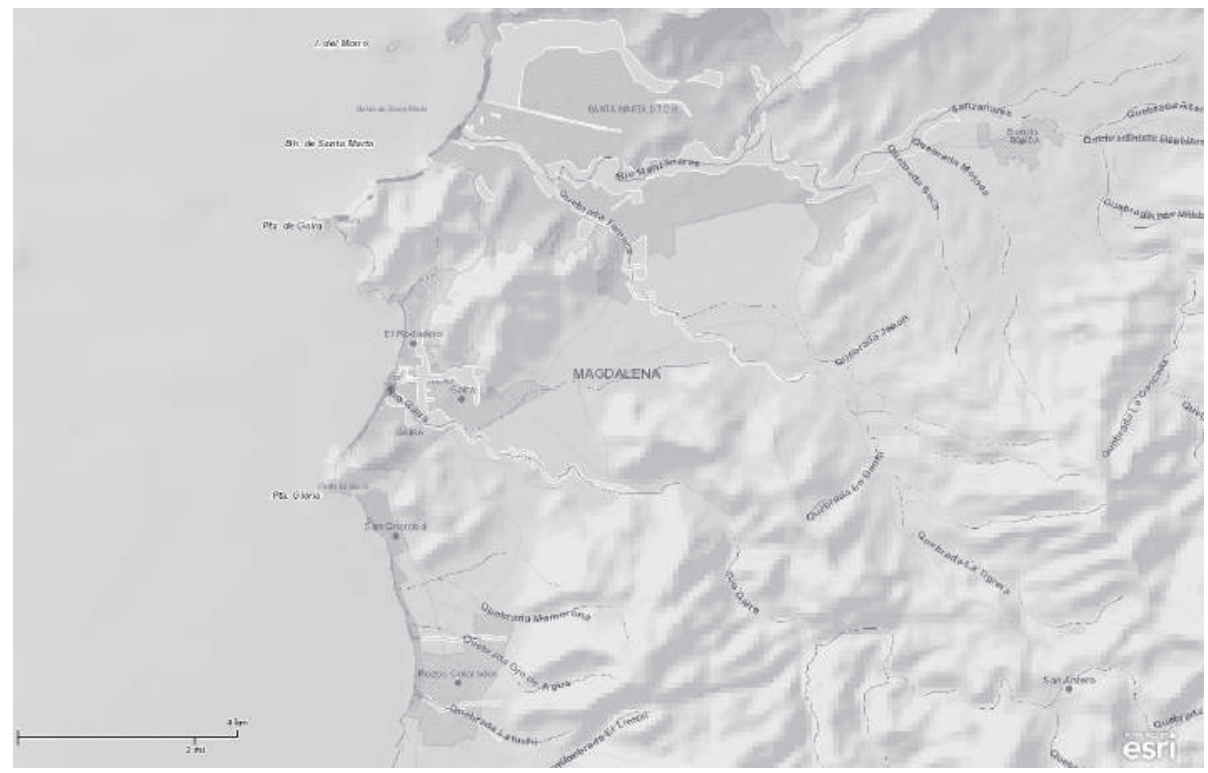

Fuente: INVEMAR.

\section{EDUCACIÓN}

La mayoría de los fenómenos asociados a la pobreza convergen en un mismo tema: la educación. Acceder a un empleo de calidad, tener una vivienda digna y, en general, gozar de unas condiciones de vida mínimas, dependen de una u otra forma del nivel educativo alcanzado. En el caso de los más pobres, la educación es la principal herramienta que les brinda la sociedad para mejorar sus condiciones de vida. Sin embargo, para que la educación sea la herramienta deseada, no basta con asistir a la escuela. En efecto, el aprendizaje debe ser garantizado a través de una educación de calidad. Si la población con menos recursos es la que menos aprende, las desventajas se mantienen y la superación de la pobreza se convierte en el logro de unos pocos (Banco Mundial, 2018). Es precisamente en este último ámbito donde se concentran los problemas de Santa Marta y que han hecho de la educación un tema directamente relacionado con la persistencia de la pobreza en la ciudad. 


\section{A. Asistencia escolar}

Según el Ministerio de Educación Nacional, la cobertura bruta y neta del sistema educativo de Santa Marta en 2016 fue de 97\% y 85\%, respectivamente. Si se trata de los más pobres, según la información del SISBEN, solo 12\% de los niños en edad escolar no asistían a centros educativos. Sin duda se ha dado un avance en materia de cobertura para el agregado del sistema educativo. A pesar de ello, no se deben olvidar las diferencias entre los distintos niveles educativos y grupos de edades.

El Cuadro 6 presenta, con base en la información del SISBEN, las tasas de inasistencia a 2017 para los niños entre 3 y 18 años, desagregando por género y zonas. Mientras que las edades de primaria y secundaria muestran un mejor desempeño en asistencia, en preescolar y educación media hay aún espacio para mejorar. Especialmente en los primeros años $(3,4$ y 5$)$, a pesar de que en el sistema educativo colombiano solo es obligatorio un grado de preescolar, más del $80 \%$ de los niños en estas edades no asisten a clases.

\section{CUADRO 6}

Santa Marta: Inasistencia escolar por edades, 2017

(porcentajes)

\begin{tabular}{|l|c|c|c|c|c|}
\hline \multirow{2}{*}{ Nivel } & \multirow{2}{*}{ Grupo etario } & \multicolumn{2}{c|}{ Cabecera } & \multicolumn{2}{c|}{ Resto } \\
\cline { 3 - 6 } & & Hombre & Mujer & Hombre & Mujer \\
\hline Jardin, Transición & $3-5$ & 89,0 & 88,2 & 89,0 & 92,2 \\
\hline Primaria & $6-10$ & 22,5 & 19,3 & 21,7 & 24,7 \\
\hline Secundaria, Media & $11-18$ & 26,8 & 35,5 & 31,3 & 32,2 \\
\hline
\end{tabular}

Fuentes: Elaboración propia con base en datos del SISBEN.

En las zonas rurales el reto es aún mayor. En estas áreas, la tasa de inasistencia en preescolar, para el caso de las mujeres, supera el 90\%. Por su parte, en educación secundaria y media, tanto para hombres como mujeres, las tasas de inasistencia son superiores a $30 \%$.

Una de las explicaciones de las diferencias en cobertura entre lo urbano y lo rural es la deserción escolar. En el Gráfico 15 se presenta la situación académica de los estudiantes en Santa Marta al finalizar el año escolar 2016. En ese año, el 


\section{GRÁFICO 15}

Santa Marta: Situación académica de los estudiantes al terminar el año lectivo, 2016

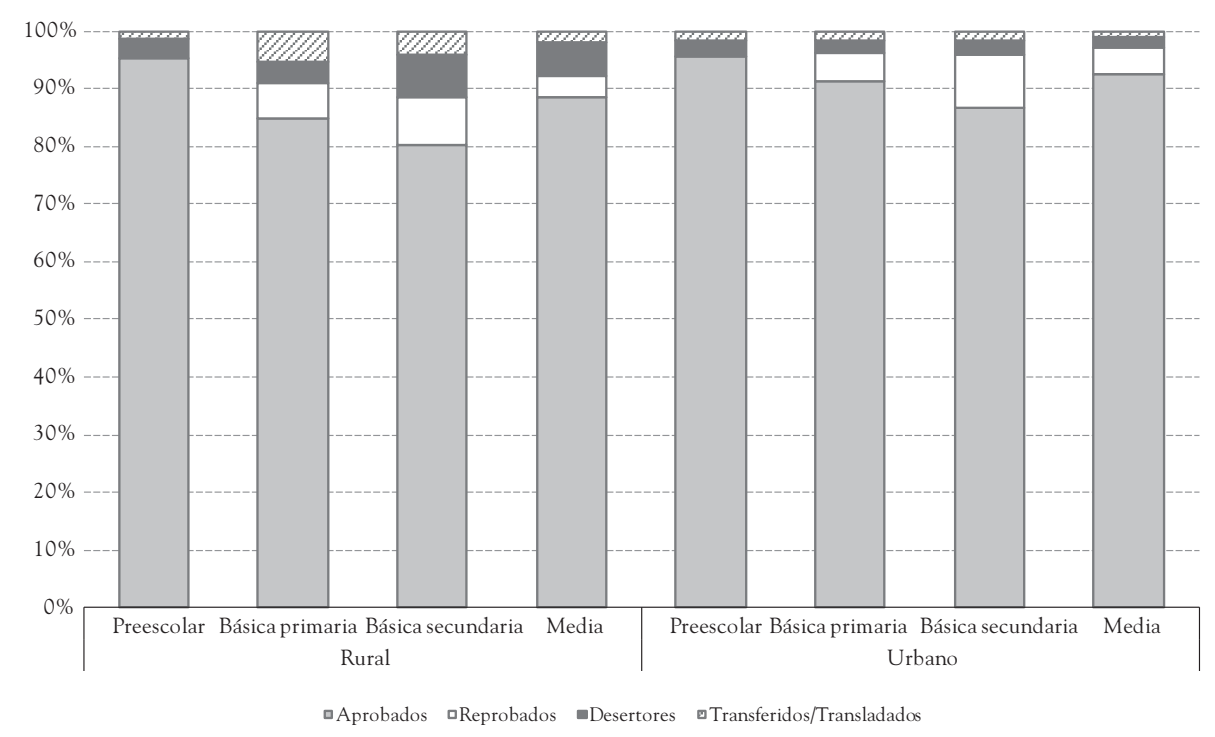

Fuentes: Elaboración propia con base en la Encuesta de Educación Formal del DANE.

porcentaje de deserción en básica secundaria en las zonas rurales fue de 7\%, comparado con $2 \%$ en las áreas urbanas. Una mayor deserción en este nivel educativo termina generando efectos negativos en la asistencia en educación media.

Según la Alcaldía Distrital de Santa Marta (2012), los factores que afectan en mayor medida la deserción en la ciudad son el desplazamiento forzado, zonas inseguras, zonas lejanas a los hogares, oferta incompleta en la sede, falta de docentes, violencia escolar, trabajo infantil y situaciones de enfermedad. La presencia de uno o más de estos factores conduce a los niños a tomar decisiones costosas para su vida, como el trabajo y la mendicidad.

Finalmente, a la inasistencia y la deserción escolar le sigue el bajo logro educativo de muchos adultos en la ciudad. En 2011, según el sISBEN, 41\% de las personas mayores de 15 años habían cursado solo primaria o no contaban con nivel educativo alguno. El Mapa 5 muestra la distribución de estas personas en los barrios de Santa Marta. 


\section{MAPA 5}

Santa Marta: Porcentaje de adultos con bajo logro educativo por barrios, 2011

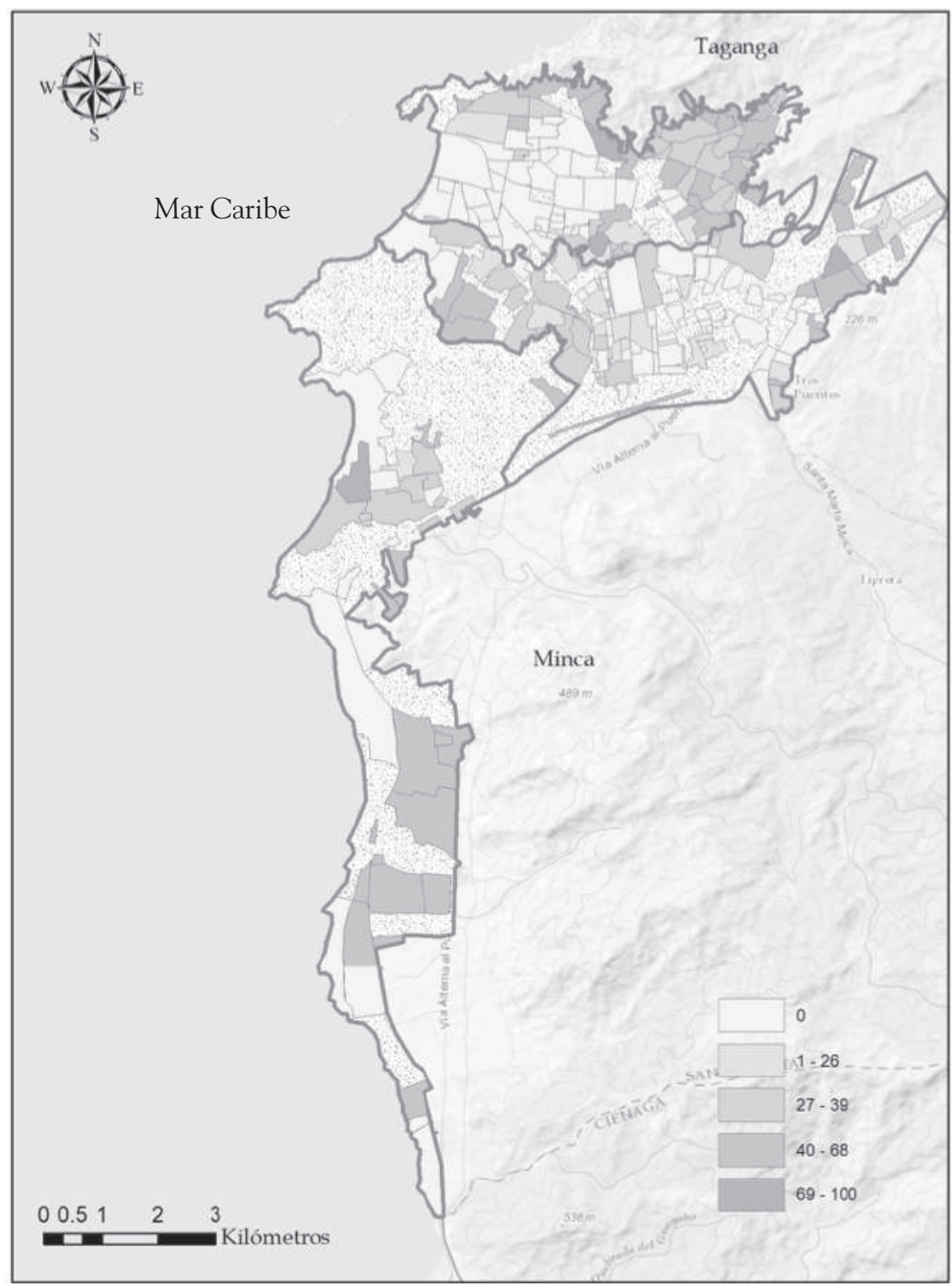

Fuentes: Elaboración propia con base en datos de la Secretaría de Planeación Distrital de Santa Marta y del SISBEN. 
En la zona urbana, los barrios que concentran la mayor población con bajo logro educativo en la Localidad 1 son Maria Cecilia, 11 de Noviembre y Timayui I y II; en la Localidad 2, Los Fundadores, San Jorge y las Tres Cruces; y en la Localidad 3, La Paz. Como vimos anteriormente, es en estos mismos barrios donde se concentran otros problemas de la ciudad como la pobreza y la informalidad. Guachaca, por su parte, es el corregimiento de la zona rural con mayor número y porcentaje de adultos con bajo logro educativo (Cuadro 7). De igual manera, como se ha evidenciado a lo largo de este trabajo, aquí también convergen otros problemas como la falta de acceso a servicios de acueducto y alcantarillado, la informalidad y la pobreza.

\section{CUADRO 7}

Santa Marta: Porcentaje de adultos con bajo logro educativo en los corregimientos de la zona rural, 2011

\begin{tabular}{|l|c|c|}
\hline \multicolumn{1}{|c|}{ Corregimiento } & $\begin{array}{c}\text { Número de adultos con } \\
\text { bajo logro educativo }\end{array}$ & $\begin{array}{c}\text { Porcentaje del total } \\
\text { de adultos }\end{array}$ \\
\hline Minca & 1.441 & 60,9 \\
\hline Taganga & 1.563 & 53,1 \\
\hline Guachaca & 6.435 & 75,5 \\
\hline
\end{tabular}

Fuentes: Elaboración propia con base en datos del SISBEN.

\section{B. Calidad educativa}

Como se mencionó antes, no es suficiente tener acceso a la educación. Es necesario garantizar el aprendizaje a través de una educación de calidad. Las pruebas Saber 11 brindan una aproximación a la situación de Santa Marta a este respecto. Los Gráficos 16, 17 y 18 muestran, para 2017, el puntaje promedio de los colegios públicos de la ciudad comparado con las 23 ciudades principales e intermedias en las competencias de matemáticas, lectura crítica e inglés. En matemáticas, la ciudad ocupó el penúltimo lugar, superando únicamente a Quibdó; en lectura crítica, el cuarto más bajo, superando a Quibdó, Riohacha y Cartagena; y en inglés, de nuevo ocupa el penúltimo lugar, solo por encima de Riohacha.

Además, para este mismo año, solo cinco de 49 instituciones educativas oficiales lograron ubicarse en las categorías más altas de desempeño de Saber 11 (C 


\section{GRÁFICO 16}

Santa Marta: Resultados de los colegios públicos en las pruebas Saber 11, 2017

(puntaje en matemáticas)

60

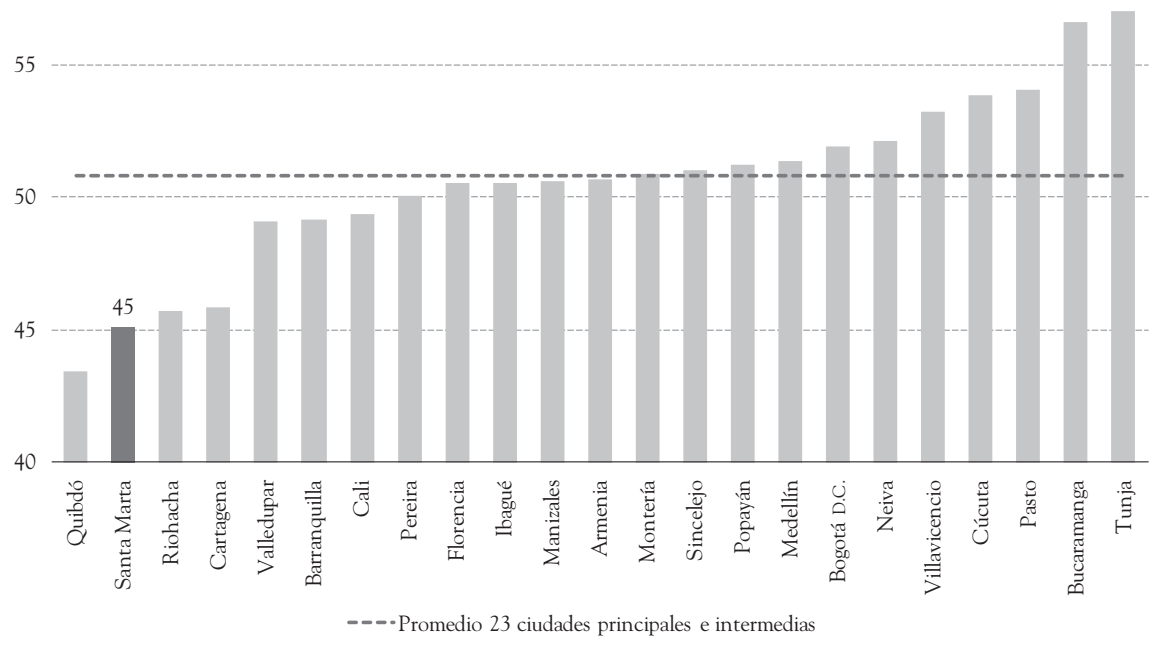

Fuentes: Elaboración propia con base en datos del Instituto Colombiano para la Evaluación de la Educación (ICFES).

\section{GRÁFICO 17}

Santa Marta: Resultados de los colegios públicos en las pruebas Saber 11, 2017 (puntaje en lectura crítica)

60

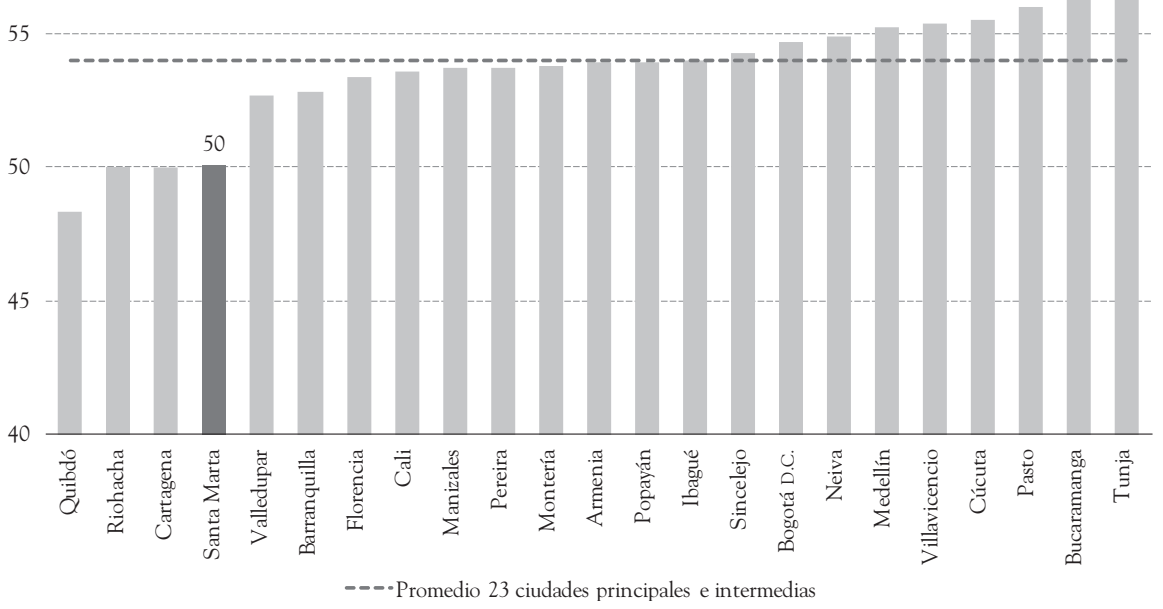

Fuentes: Elaboración propia con base en datos del Instituto Colombiano para la Evaluación de la Educación (ICFES). 


\section{GRÁFICO 18}

Santa Marta: Resultados de los colegios públicos en las pruebas Saber 11, 2017

(puntaje en inglés)

60

55

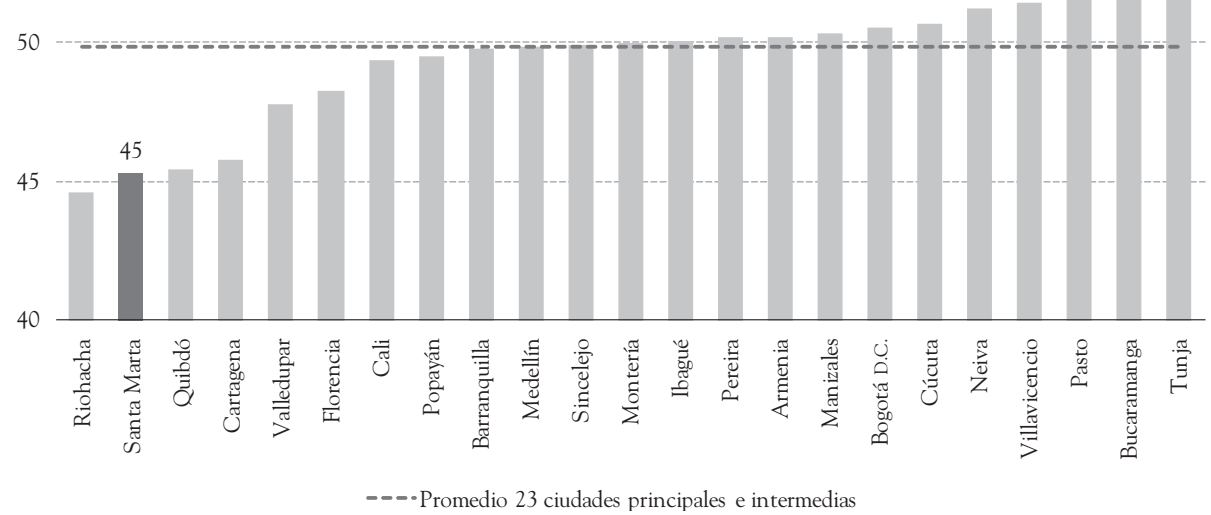

Fuentes: Elaboración propia con base en datos del ICFES.

y D). Los deficientes resultados de los estudiantes y de las instituciones educativas dan muestra de los retos que enfrenta la ciudad con relación al aprendizaje efectivo de sus estudiantes.

\section{Otros factores relacionados con la educación}

Diversos factores asociados a estudiantes, docentes y escuelas ayudan a explicar los bajos rendimientos académicos observados. Iniciando con los más pequeños, la falta de atención en edades tempranas y la inasistencia en los primeros grados de preescolar podrían estar limitando la adquisición de competencias en la infancia tardía y la adolescencia (Banco Mundial, 2018). En Santa Marta, según datos del SISBEN, en 2016 el 33\% de los niños entre las edades de 0 a 5 años no tenía acceso a los servicios para el cuidado integral de la primera infancia. La desnutrición o la 
falta de atención en los primeros años hacen que los niños lleguen a las escuelas con una baja disposición para aprender.

Pero el problema no está solo en los niños. Los docentes poco calificados o desmotivados pueden ser también parte de la explicación del bajo rendimiento. En Santa Marta, el 24\% de los docentes cuenta con un nivel de educación profesional o mayor (Gráfico 19). Si se compara contra las otras 23 ciudades principales e intermedias, Santa Marta solo supera a Quibdó y Cali en el nivel educativo de sus docentes, ubicándose muy por debajo del total nacional.

En cuanto a las jornadas de las escuelas, diversos estudios han encontrado para Colombia los efectos positivos sobre la calidad educativa que tiene estudiar en jornada completa (Bonilla, 2011; García, et al., 2013). Santa Marta, como muchas otras ciudades del país, está rezagada a este respecto. En 2016, apenas 5\% de los alumnos se encontraban matriculados en jornada única. La implementación de esta jornada podría traer efectos positivos para la calidad educativa en la ciudad, siempre y cuando se coordine con otras dimensiones, como el mejoramiento de la planta docente, los diseños curriculares y la infraestructura de los colegios.

\section{GRÁFICO 19}

Santa Marta: Docentes con nivel educativo profesional o mayor, 2016 (porcentajes)

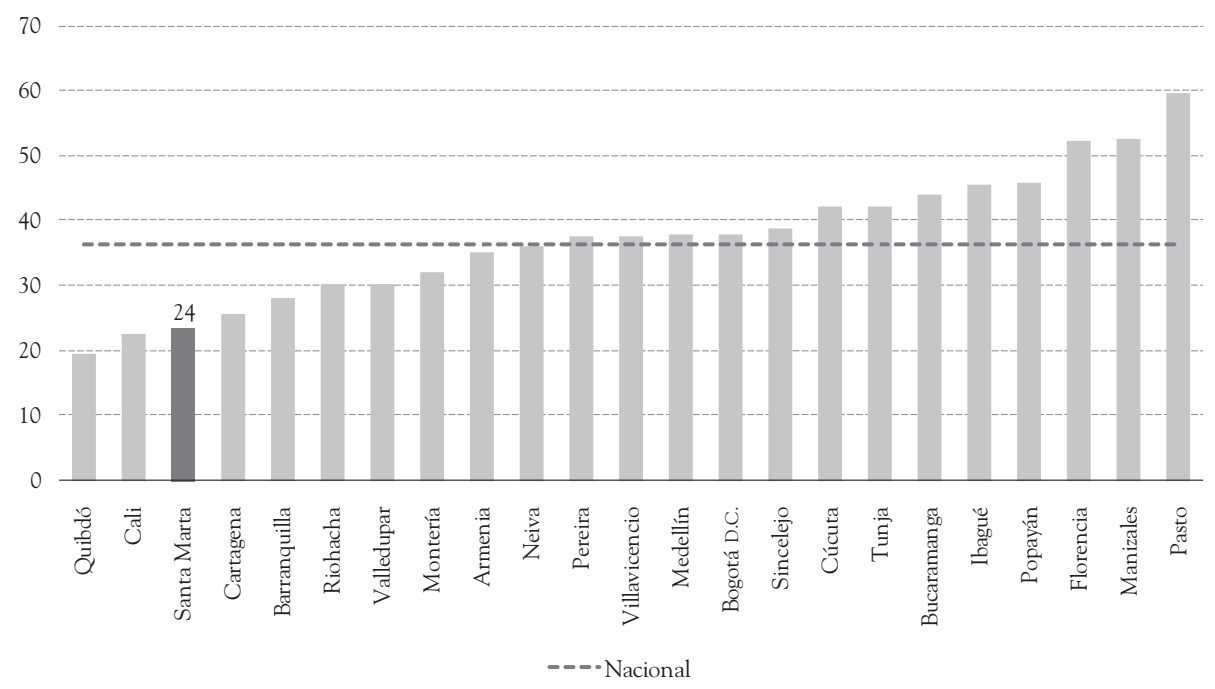

Fuentes: Elaboración propia con base en la Encuesta de Educación Formal del DANE. 
Un último factor con grandes efectos tanto en calidad como en cobertura es la infraestructura escolar. Según la Alcaldía Distrital de Santa Marta (2012), dos de cada tres establecimientos educativos no cuentan con una dotación de materiales, servicios y mobiliario para la efectiva enseñanza y aprendizaje de los niños. La mayoría de las instituciones educativas oficiales tienen deficientes instalaciones sanitarias y mala calidad en la prestación de los servicios públicos de electricidad, aseo, acueducto y alcantarillado. Además de la infraestructura, muchos de estos colegios presentan amenazas de deslizamientos e inundaciones y, en algunos casos, se encuentran ubicados en lugares con problemas de accesibilidad.

\section{INVERSIONES PARA SUPERAR EL REZAGO EN POBREZA EN 2030}

A continuación se presentan las inversiones requeridas para que, en un período de 12 años, la pobreza de Santa Marta se ubique en el promedio que tendrán las 23 ciudades principales e intermedias en 2030. La proyección supone que se mantienen las tendencias actuales en reducción de pobreza. Las inversiones van dirigidas a los sectores con los indicadores más críticos en la ciudad que, como se evidencia a lo largo de este trabajo, corresponden a más de uno. Al final, se sugieren algunas posibles fuentes de financiación para las inversiones propuestas. El análisis realizado, las propuestas y sus costos asociados, van en línea con lo presentado por Ayala y Meisel (2017), Bonilla-Mejía y Martínez-González (2017), y Bonet-Morón y Pérez-Valbuena (2017) para los casos de Cartagena y la Región Caribe. Estos dos últimos estudios fueron presentados como parte de la iniciativa Casa Grande Caribe, que trabaja por la identificación de las inversiones necesarias para brindar solución al atraso relativo de la Costa Caribe colombiana. ${ }^{2}$

\section{A. Inversión en educación}

Como lo revelan las cifras, el mayor reto de Santa Marta está en la calidad de su educación. Es por ello que la propuesta más ambiciosa gira en torno a este

\footnotetext{
${ }^{2}$ Mayor información de Casa Grande Caribe en www.casagrandecaribe.com.co
} 
tema y, más específicamente, a generar un progreso en los factores asociados a su calidad, como lo son docentes, infraestructura, nutrición y tiempo en el colegio.

Con relación a este último factor, es indispensable dar un impulso a la implementación de la jornada única, una política con importantes efectos en la calidad del aprendizaje. El mayor tiempo en las escuelas y la menor exposición que esto implica a los riesgos de la calle, ha demostrado tener repercusiones positivas en los resultados académicos de los estudiantes en Colombia (Bonilla, 2011; Hincapié, 2016). De igual manera, ha contribuido a la reducción de las tasas de deserción y repitencia (García, et al., 2013). Por otro lado, asistir a un establecimiento de jornada única implica recibir el almuerzo en el colegio, con efectos positivos en la nutrición y en la disposición al aprendizaje de los estudiantes.

No obstante, el éxito de la jornada única en el mejoramiento de la calidad educativa depende de qué tanto se coordinen los esfuerzos con otras áreas, como la planta docente, la infraestructura escolar, los diseños curriculares y la administración de las escuelas. En este último tema es clave la capacidad institucional de agentes como los rectores y la Secretaría de Educación. Con base en lo anterior, se proponen cuatro clases de inversiones para mejorar la calidad de la educación en Santa Marta: 1) aumentar el número de estudiantes en jornada única; 2) mejorar la infraestructura escolar; 3 ) invertir en la educación de docentes en servicio; y 4) fortalecer la capacidad institucional de la Secretaría de Educación y las rectorías de las escuelas.

Iniciando con la propuesta de jornada única y en línea con Bonilla-Mejía y Martínez-González (2017), la meta sugerida es que, a 2030, el 60\% de los alumnos del sistema educativo asista a colegios en jornada única y que, además, se alcance una cobertura del $100 \%$ en educación primaria, secundaria y media. Tanto en cobertura como en implementación de la jornada única, esta propuesta implica una mayor demanda de estudiantes en el sistema y, por lo tanto, requiere de una importante inversión en infraestructura educativa.

Con base en los datos de cobertura del Ministerio de Educación Nacional (MEN) para 2016, alcanzar la cobertura total en educación básica en Santa Marta implica ampliar la capacidad del sistema escolar público en $8,9 \%$, equivalente a 7.821 alumnos adicionales, para un total de 95.428 matriculados en 2016. Para conocer la cantidad de cupos adicionales que se deben generar para cumplir la meta a 2030 es necesario proyectar el número de matriculados hasta esa fecha. Usando las proyecciones de población de Pachón (2012), se obtiene una demanda total en el sistema educativo a 2030 de cerca de 117.700 alumnos. Por lo tanto, 
y teniendo en cuenta la meta del $60 \%$, el número de matriculados en jornada única debería ser de aproximadamente 70.600. Según datos del MEN a 2017, hay 9.999 alumnos matriculados en jornada única en la ciudad; es decir, se deben crear aproximadamente 60.600 nuevos cupos en jornada única para cumplir la meta (Cuadro 8).

Dos acciones se proponen para crear nuevos cupos: 1) construcción de infraestructura nueva; y 2) adecuación de espacios existentes en el colegio, como bibliotecas y laboratorios. Si se supone que el 30\% de los cupos nuevos se logra con adecuación de espacios y el restante con nueva infraestructura, de los 60.600 cupos, solo 42.400 requerirán aulas nuevas. Con un número promedio de 40 estudiantes por salón, atender esta nueva demanda de estudiantes implica construir alrededor de 1.060 aulas (Cuadro 8).

\section{CUADRO 8}

Santa Marta: Inversión en educación

\begin{tabular}{|c|c|c|c|}
\hline \multirow{8}{*}{$\begin{array}{l}\text { Jornada única y } \\
\text { mejoramiento } \\
\text { infraestructura }\end{array}$} & \multicolumn{2}{|l|}{ Cupos nuevos } & 60.626 \\
\hline & \multicolumn{2}{|l|}{ Aulas nuevas } & 1.061 \\
\hline & \multirow{3}{*}{ Inversión infraestructura (USD \$) } & Ampliación & 33.482 .953 \\
\hline & & Colegios nuevos & 36.838 .550 \\
\hline & & Mejoramiento sedes & 3.000 .000 \\
\hline & \multirow{2}{*}{$\begin{array}{l}\text { Costos adicionales (USD \$) } \\
\text { (acumulado 2019-2030) }\end{array}$} & SGP & 44.258 .897 \\
\hline & & Alimentación escolar & 83.818 .995 \\
\hline & \multicolumn{2}{|l|}{ Total (USD \$) } & 201.399 .396 \\
\hline \multirow{4}{*}{$\begin{array}{l}\text { Maestrías } \\
\text { docentes }\end{array}$} & \multicolumn{2}{|l|}{ Meta docentes con posgrado 2030} & 1.413 \\
\hline & \multicolumn{2}{|l|}{ Faltan con posgrado } & 839 \\
\hline & \multicolumn{2}{|c|}{ Costo aproximado por maestría (USD \$) } & 6.000 \\
\hline & \multicolumn{2}{|l|}{ Total (USD \$) } & 5.034 .000 \\
\hline \multirow{3}{*}{$\begin{array}{c}\text { Fortalecimiento } \\
\text { institucional }\end{array}$} & \multicolumn{2}{|c|}{ Costo programa Secretaría de Educación (USD \$) } & 41.762 \\
\hline & \multicolumn{2}{|c|}{ Costo programa a 27 rectorías (USD \$) } & 283.500 \\
\hline & \multicolumn{2}{|l|}{ Total (USD \$) } & 325.262 \\
\hline & \multicolumn{2}{|c|}{ Inversión TOTAL en Educación (USD \$) } & 206.758 .658 \\
\hline
\end{tabular}

Fuentes: Elaboración propia con base en Bonilla-Mejía y Martínez-González (2017). 
Según el MEN, cuando se trata de una ampliación, el costo promedio de construcción y dotación de una nueva aula de clase es de usD $\$ 45.084$. Por otro lado, cuando es una sede nueva, el costo es de USD $\$ 115.740$. Se propone que el 30\% de las aulas se construya en colegios nuevos y el restante con ampliaciones de infraestructura existente. Esto generaría una inversión total en ampliaciones y colegios nuevos de aproximadamente USD $\$ 33$ y usD $\$ 37$ millones, respectivamente (Cuadro 8).

Por otro lado, es indispensable invertir en el mejoramiento de la infraestructura existente. A partir de un análisis minucioso realizado por la Alcaldía y la Secretaria de Educación en 2012, la infraestructura de 15 de 69 establecimientos educativos en Santa Marta se clasifica en mal estado. Se propone, entonces, destinar un monto de recursos para el mejoramiento de la infraestructura en estos planteles educativos. A pesar de que cada institución cuenta con necesidades particulares de infraestructura, para calcular el costo de esta inversión se incluyen en la propuesta la reconstrucción de las baterías sanitarias y el comedor escolar, y la construcción y dotación de una biblioteca. El costo estimado de esta inversión es de aproximadamente USD \$200 mil por establecimiento educativo; es decir, se asignarían aproximadamente USD \$3 millones para este propósito.

Pero más allá de la infraestructura, la jornada única implica mayores transferencias, principalmente para el pago de la nómina docente. Por un lado, el MEN reconoce un 20\% adicional por alumno matriculado en jornada única. Por otro, con relación a la alimentación escolar, además del complemento nutricional se deben transferir recursos para brindar el almuerzo en el colegio a los alumnos matriculados en jornada única.

Según Colombia Compra Eficiente, el costo anual promedio del almuerzo por alumno y del complemento nutricional es de USD $\$ 221$ y usD $\$ 151$, respectivamente. Si se supone que se alcanzan la metas de cobertura y alumnos en jornada única a 2030, el resultado sería un costo adicional acumulado entre 2019 y 2030 , de USD $\$ 44$ y USD $\$ 84$ millones, para SGP y alimentación escolar, respectivamente (Cuadro 8).

Habiendo especificado las inversiones para lograr la implementación de la jornada única, es importante garantizar que el tiempo adicional en las escuelas se use de manera adecuada. Es aquí donde la formación de los docentes juega un papel fundamental. Una de las políticas que ha impulsado la formación de los docentes en servicio es el Programa Para la Excelencia Docente y Académica Todos a Aprender 2.0, que ha beneficiado a más de 1.000 docentes y 30.000 alumnos en 
Santa Marta. A pesar de la existencia de este y otros programas del MEN, como se observó en el Gráfico 19, Santa Marta continúa siendo una de las ciudades con mayor rezago educativo en sus docentes. Es por esto que dentro de esta propuesta, se incluye un programa complementario a los implementados por el MEN, que busca impulsar aún más la formación de los docentes en servicio en la ciudad.

En particular y con base en Bonilla-Mejía y Martínez-González (2017), se propone la financiación de créditos beca para la formación de docentes en servicio, siendo exclusivamente para maestrías de alta calidad y asignadas con base en el mérito. Igual a la propuesta de estos autores, se propone llegar a $40 \%$ de docentes con maestría en 2030. Teniendo en cuenta que a 2016 había 2.872 docentes en la ciudad y que según el DANE, alrededor del $24 \%$ de estos contaban con maestría, para alcanzar la meta de $40 \%$ en 2030 es necesario financiar las maestrías de aproximadamente 839 docentes en Santa Marta. Actualmente el costo de una maestría oscila alrededor de los USD $\$ 6.000$, lo que implica un costo adicional de esta propuesta de alrededor de USD \$5 millones (Cuadro 8).

Finalmente, es necesario alinear los propósitos de todos los agentes para el efectivo aprendizaje en las escuelas. Es indispensable, por lo tanto, invertir en el fortalecimiento institucional de la Secretaría de Educación y los directivos de las escuelas. A este efecto son dos las propuestas: 1) un programa de acompañamiento a la Secretaria de Educación; y 2) la formación de rectores de los establecimientos educativos oficiales. La Fundación Empresarios por La Educación ofrece un ejemplo de este tipo de intervenciones. Uno de sus programas, conocido como Rectores Líderes Transformadores, apoya la formación integral de los rectores como seres humanos y líderes para mejorar su desempeño en todos los ámbitos de la gestión escolar. Por otro lado, la Fundación también lidera programas de acompañamiento a las Secretarías de Educación, que permiten fortalecer su gestión administrativa y crear importantes vínculos con el sector empresarial.

Se propone llevar a cabo el programa de acompañamiento a la Secretaría, el primer año de cada gobierno. Por su parte, la formación de rectores se sugiere que sea dirigida a aquellas escuelas con los niveles más bajos de desempeño en las pruebas Saber 11. El costo aproximado de estos programas es de USD $\$ 13.900$, en el caso del acompañamiento a la Secretaría y de USD $\$ 10.500$ por establecimiento educativo, en el caso de la formación de rectores. Teniendo en cuenta que en el segundo semestre de 2017 fueron 27 los colegios clasificados en los niveles más bajos de desempeño ( $\mathrm{C}$ y $\mathrm{D}$ ) y que se debería realizar el acompañamiento a la Secretaría tres veces durante el período 2019 - 2030, el valor total de estas inversiones sería 
de aproximadamente USD $\$ 42.000$ en el caso de la Secretaría de Educación y de USD \$293.500 para el acompañamiento a las rectorías (Cuadro 8).

En síntesis, la inversión en educación que abarca las políticas de jornada única, mejoramiento de infraestructura, maestrías de docentes y fortalecimiento institucional tendría un costo total de aproximadamente USD \$207 millones. El detalle de todas las intervenciones mencionadas se presenta en el Cuadro 8.

\section{B. Reubicación de viviendas y conexión a los servicios de acueducto y alcantarillado}

Como se observó antes, en algunos sectores de Santa Marta los habitantes deben enfrentarse constantemente a las amenazas del cambio climático. Muchos de estos sectores coinciden, a su vez, con un gran número de hogares en condición de pobreza que, además de su escasez de recursos, se encuentran altamente expuestos a fenómenos como inundaciones y deslizamientos de tierra que amenazan con destruir sus viviendas.

La reubicación de esta población es, entonces, un tema central de las políticas de reducción de la pobreza en la ciudad. Según Cuervo, et al. (2015), unas 25.000 personas viven en zonas de riesgo de inundación, erosiones y deslizamientos de tierra. Esto equivale al 5,5\% de la población en Santa Marta que, si se tiene en cuenta un número promedio de cinco personas por hogar, significa que son alrededor de 5.000 familias las que habitan en estas zonas.

A pesar de que las cifras anteriores brindan una aproximación al número de viviendas que requieren ser reubicadas, el éxito de esta política depende de la efectiva identificación y georreferenciación de las familias. Es indispensable saber quiénes son, dónde se encuentran ubicadas, a qué riesgos se enfrentan y si el riesgo es o no mitigable. Así pues, una primera inversión para la reubicación de las familias es llevar acabo un censo que tenga como principal propósito dar respuesta a estas preguntas. Con base en información sobre una experiencia similar en Cartagena, este primer paso tendría un costo aproximado por familia de USD \$23 dólares (Ayala y Meisel, 2017).

Luego de censar a la población, la siguiente fase es la reubicación de las familias. En Colombia han existido experiencias en este tipo de intervenciones. Una de ellas es el programa de viviendas gratis del Gobierno Nacional, que hace parte del cumplimiento de las metas del Gobierno de crear empleo y reducir la pobreza, y da prioridad a familias víctimas del desplazamiento. Este programa ha llegado a 
Santa Marta a través de proyectos como la Urbanización Ciudad Equidad, que otorgó viviendas a alrededor de 20.000 personas entre desplazados, madres cabeza de familia, desmovilizados y afectados por la ola invernal (Benjumea, 2015).

Las viviendas en el programa del Gobierno Nacional tienen un costo aproximado de 70 salarios mínimos legales mensuales vigentes, equivalente a alrededor de USD \$18 mil. Si se toma como aproximación el número de hogares viviendo en zonas de riesgo, reubicar a 5.000 familias en Santa Marta tendría un costo aproximado de UsD $\$ 91$ millones (Ayala y Meisel, 2017).

Pero no basta con reubicar a las familias. Experiencias como la de la Urbanización Ciudad Equidad en Santa Marta han dejado algunas lecciones para tener en cuenta. Por un lado, se debe garantizar que las familias necesitadas sean las que obtengan y efectivamente disfruten los beneficios de la intervención. Por otro, y más importante para el caso de Santa Marta, se debe garantizar el acceso a los servicios de acueducto y alcantarillado en estas nuevas viviendas. Según el Ministerio de Vivienda (2013), garantizar la conexión a acueducto y alcantarillado de un hogar tiene un costo aproximado de USD $\$ 1.200$. Es decir, para las 5.000 familias reubicadas esta política tendría un costo de alrededor USD \$6 millones. Con esta última intervención, la reubicación de las viviendas, garantizando su conexión a los servicios de acueducto y alcantarillado, tendría un costo aproximado de UsD $\$ 97$ millones.

No obstante, y como se mostró arriba, un gran número de viviendas en la ciudad, a pesar de no estar ubicadas en zonas de riesgo, carecen de conexión a los servicios de acueducto y alcantarillado. Según información del SISBEN, en 2017 eran aproximadamente 57.000 las familias que no contaban con ninguno de estos dos servicios. Teniendo en cuenta el mismo costo por familia de USD $\$ 1.200$, se deben destinar aproximadamente USD $\$ 69$ millones para conectar a estas 57.000 familias a los servicios de acueducto y alcantarillado.

Cabe aclarar que la propuesta presentada no pretende superar los problemas de la infraestructura de los sistemas de acueducto y alcantarillado en la ciudad, ni aumentar las fuentes de abastecimiento de agua. Se trata simplemente de inversiones para superar la condición de pobreza de un sector de la población.

\section{Capacitación y vinculación laboral}

Sin duda alguna, las propuestas en educación básica son un gran impulso para la creación de empleos productivos y de calidad en la ciudad. No obstante, los 
efectos positivos de estas propuestas sobre las condiciones de empleabilidad de la población pueden tardar muchos años en producirse. Ante las alarmantes cifras de informalidad en la ciudad, es necesario complementar esta inversión en educación básica con otras propuestas que permitan, en el corto plazo, ir avanzando en la superación de las problemáticas del empleo en la ciudad.

Para lograr esto último, una de las propuestas es el fortalecimiento de la educación terciaria, un eslabón del sistema educativo que reviste gran importancia en el crecimiento y desarrollo del capital humano en una sociedad. Aumentando las capacidades de las personas, la educación terciaria podría lograr una mayor articulación entre la demanda y la oferta laboral de la ciudad, con importantes repercusiones en ingresos y calidad de los empleos en la población (Oketch, et al., 2014).

Para el caso específico de Santa Marta, según encuestas realizadas a las empresas de la cadena de valor del turismo en la ciudad, las áreas que demandan más mano de obra son mesa y bar, y cocina y culinaria. Por otro lado, con relación a los proyectos de infraestructura en la ciudad, hay importantes requerimientos en áreas como administración, ornamentación e hidrosanitaria, mecánica, auxiliares marítimos y construcción. En efecto, muchas de las labores mencionadas requieren como mínimo un nivel de educación técnica que podría ser alcanzado a través del fortalecimiento de la educación terciaria (Morón, et al., 2011).

Con base en lo anterior, se propone ampliar la oferta de carreras técnicas y tecnológicas en la ciudad a través de una inversión en sedes y programas del SENA. Barranquilla cuenta con una experiencia en este tema que puede servir como modelo para Santa Marta. En esta ciudad se planteó un proyecto ambicioso, que involucra la creación de 19 sedes del SENA con capacidad para atender hasta 100.000 estudiantes por año. El costo total estimado de esta propuesta fue de COP $\$ 119.682$ millones, equivalentes a unos UsD $\$ 40$ millones. Esto quiere decir que, por estudiante atendido, la intervención tendría un costo de USD $\$ 400$.

En 2017 según información del DANE, Santa Marta tenía unas 150.000 personas para capacitar, entre desempleados e informales. En consecuencia, realizar una intervención como esta en la ciudad tendría un costo aproximado de USD \$60 millones.

En el Cuadro 9 se muestra el costo total de esta y todas las propuestas presentadas para llevar la pobreza de Santa Marta al promedio de las 23 ciudades principales e intermedias en 2030. En total, estas suman un gran total de USD \$433 millones que, como se mencionó anteriormente, corresponden a inversiones en 
CUADRO 9

Santa Marta: Inversión total por sectores

\begin{tabular}{|l|c|c|c|}
\hline \multicolumn{1}{|c|}{ Sector } & Beneficiarios & $\begin{array}{c}\text { Millones de } \\
\text { dólares }\end{array}$ & $\begin{array}{c}\text { Miles de millones } \\
\text { de pesos }\end{array}$ \\
\hline Educación & 117.700 estudiantes & 207 & 621 \\
\hline Reubicación viviendas & 5.000 hogares & 97 & 291 \\
\hline $\begin{array}{l}\text { Conexión a servicios de } \\
\text { acueducto y alcantarillado }\end{array}$ & 57.000 hogares & 69 & 207 \\
\hline $\begin{array}{l}\text { Capacitación y vinculación } \\
\text { laboral }\end{array}$ & 150.000 personas & 60 & 180 \\
\hline Total & 433 & 1.299 \\
\hline
\end{tabular}

Fuente: Elaboración propia.

los sectores más críticos de la ciudad, los cuales de ninguna forma logran abarcar todas las problemáticas que se viven en la ciudad. Además, las cifras presentan solo una aproximación al valor de las inversiones. Se requiere de un análisis detallado en el contexto de Santa Marta para obtener el valor real de todas las propuestas presentadas.

\section{Financiamiento}

Luego de conocer el monto de las inversiones a realizar, es importante evaluar cuáles podrían ser las fuentes de ingreso para financiarlas. Para ello es necesario conocer de dónde provienen los recursos de la ciudad y en dónde es posible encontrar espacios de mejora para lograr ingresos adicionales. ${ }^{3}$

En 2016, según información de las ejecuciones presupuestales, los ingresos totales de Santa Marta sumaron Cop $\$ 685.143$ millones. De estos, las dos fuentes de mayor importancia fueron las transferencias nacionales, con una participación del 60\%, y los ingresos tributarios, con alrededor del 30\%. Como se observa

3 El análisis de esta sección se basa en Bonet-Morón y Pérez-Valbuena (2017) para el caso de la Región Caribe colombiana. 
en el Gráfico 20, a pesar de las caídas observadas en algunos períodos, en general hubo un crecimiento positivo de ambas cuentas en el transcurso de la última década.

De igual manera, como es usual en la mayoría de municipios en Colombia, se observa una alta dependencia de las transferencias nacionales. Esto último es impulsado por dos factores importantes que le asignaron mayores responsabilidades al municipio: la Constitución Política de 1991 y la categorización de Santa Marta como Distrito Turístico, Cultural e Histórico en 1989.

En este contexto, surgen dos aspectos a evaluar: qué tanto esfuerzo fiscal se realiza en el recaudo de recursos propios (ingresos tributarios y no tributarios) y qué tan eficiente es el gobierno local en la ejecución de los gastos designados.

Con relación a la primera pregunta, es difícil conocer con precisión la capacidad fiscal de los municipios de Colombia, principalmente por la falta de información sobre las bases tributarias. Sin embargo, Bonet-Morón y Ayala-García (2016) calcularon una aproximación a este indicador. Para hacerlo, acudieron a

\section{GRÁFICO 20}

Santa Marta: Fuentes de ingreso, 2003 - 2016

(millones de pesos corrientes)

800.000

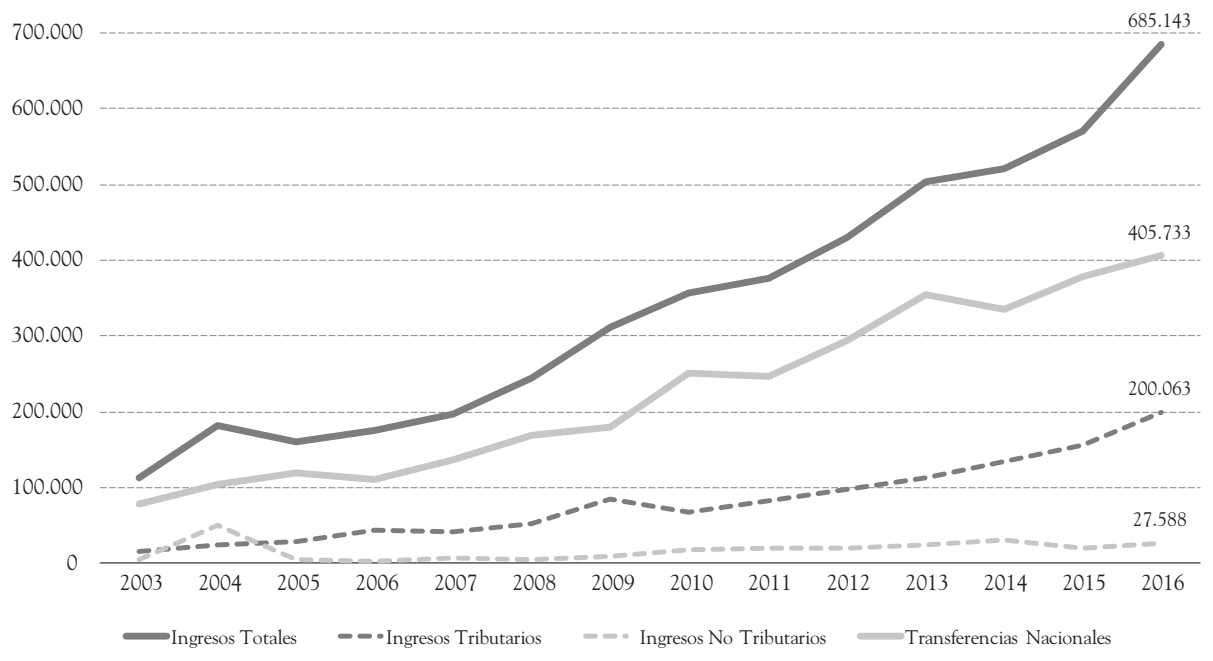

Fuentes: Elaboración propia con base en Ejecuciones Presupuestales de los Municipios, DNP. 
algunos determinantes observables del recaudo, como el tamaño poblacional y el PIB per cápita. A partir de estos y usando una metodología cuantitativa conocida como Análisis Envolvente de Datos, calculan la capacidad fiscal para todos los municipios colombianos en 2014. El Gráfico 21 presenta los resultados para Santa Marta.

En 2014, la ciudad contaba con una capacidad fiscal de aproximadamente COP $\$ 475.935$ millones, frente a un recaudo efectivo de cop $\$ 163.722$ millones. Lo anterior quiere decir que, en ese año, el potencial recaudatorio era cercano a los cop $\$ 312.213$ millones. Si, además, se calcula la eficiencia recaudatoria, entendida como la participación del recaudo efectivo en la capacidad fiscal total del municipio, esta resulta de $34 \%$.

Pero, ¿de dónde puede provenir este potencial recaudatorio que encuentran los autores para Santa Marta? El impuesto predial es parte de la respuesta a este

\section{GRÁFICO 21}

Santa Marta: Capacidad fiscal y recaudo efectivo, 2014

(millones de pesos corrientes)

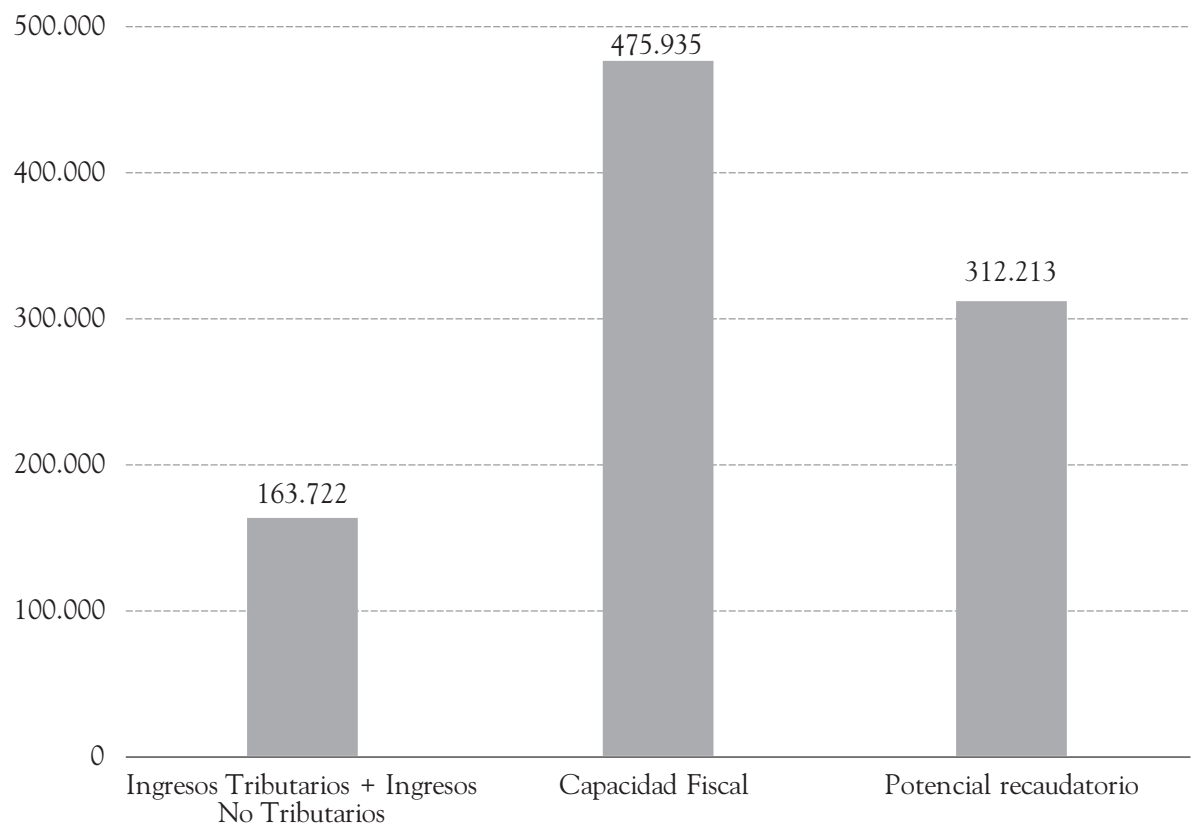

Fuentes: Bonet-Morón y Ayala-García (2016). 
interrogante. En 2016, el avalúo catastral en la ciudad fue de aproximadamente COP $\$ 10$ billones, ocupando el noveno lugar con mayor valor de catastro entre las 23 ciudades principales e intermedias. A pesar de lo anterior, Santa Marta fue en este mismo año, la octava ciudad con menor predial pagado por cada millón de pesos de avalúo, COP $\$ 5.255$ en este caso (Gráfico 22). Incluso si se compara con ciudades con menor avalúo catastral, como Ibagué y Manizales, el recaudo del impuesto predial en estas se ubica por encima del recaudo en Santa Marta (Gráfico 23). A pesar de que diversos factores pueden influir en la diferencia de recaudo entre estas ciudades, las cifras permiten entrever que aún existe espacio para mejorar en el recaudo de este gravamen.

Lo anterior solo se refiere al impuesto predial. Sin embargo, el potencial recaudatorio calculado por Bonet-Morón y Ayala-García (2016) para Santa Marta revela que probablemente también hay espacio para mejorar en el recaudo

\section{GRÁFICO 22}

Ciudades principales e intermedias de Colombia:

Predial pagado por cada millón de pesos de avalúo catastral, 2016 10.000

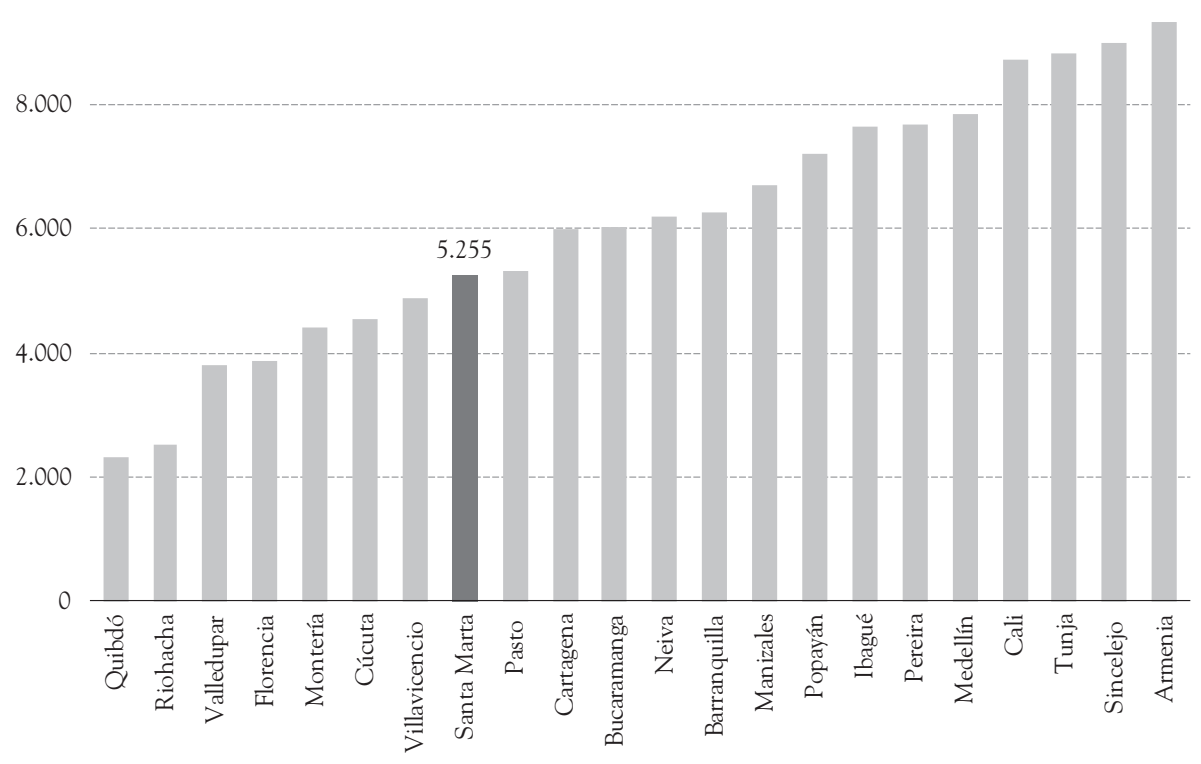

Fuentes: Elaboración propia con base en datos de Instituto Geográfico Agustin Codazzi (IGAC) y Ejecuciones Presupuestales de los Municipios, DNP. 


\section{GRÁFICO 23}

Ibagué, Manizales y Santa Marta: Impuesto predial y avalúo catastral (millones de pesos corrientes)

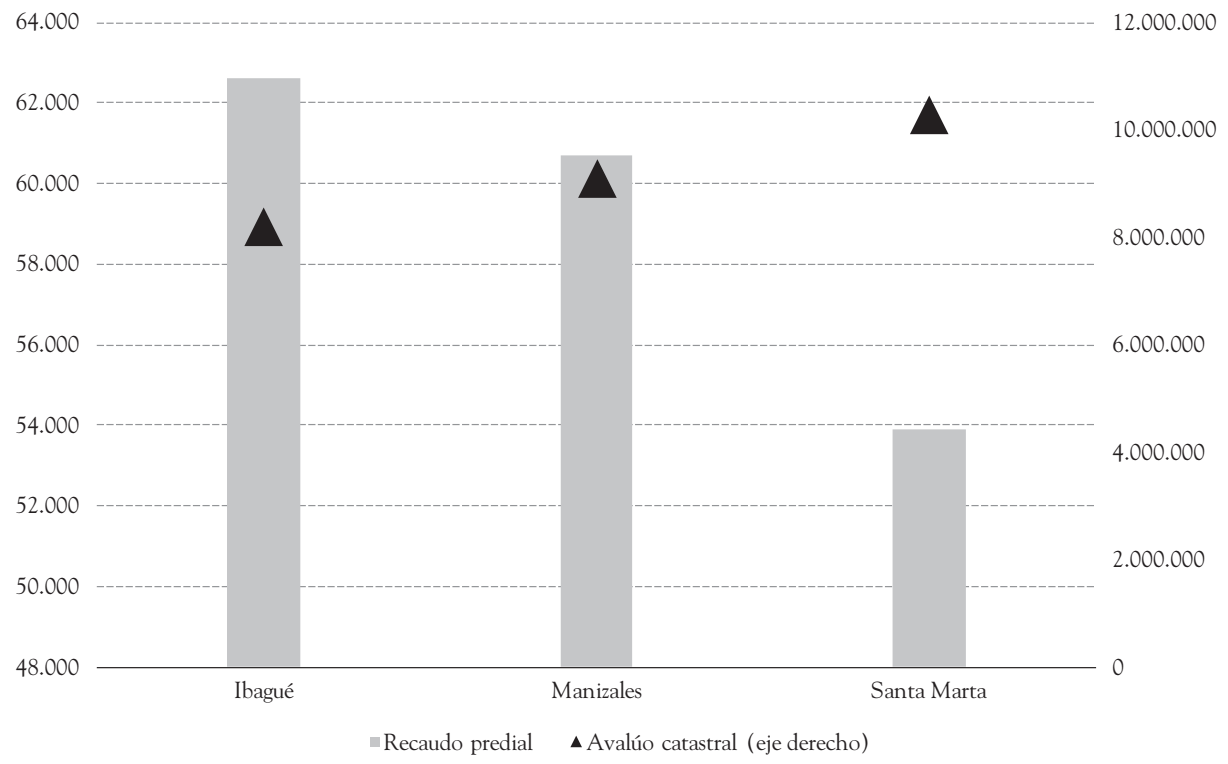

Fuentes: Elaboración propia con base en datos de IGAC y Ejecuciones Presupuestales de los Municipios, DNP.

de otros impuestos locales. Para conocer con precisión qué tantos recursos adicionales se podrían generar a 2030, se calcula el potencial recaudatorio en dos escenarios distintos: 1) cuando la eficiencia se mantiene en 34\%; y 2) cuando esta se aumenta hasta 75\% (Bonet-Morón y Pérez-Valbuena, 2017). El resultado obtenido es que en estos 12 años, se podrían tener recursos adicionales de aproximadamente cOP $\$ 4$ billones o USD $\$ 1.300$ millones. El Gráfico 24 muestra la distribución de estos recursos a través de los años considerados.

Por último, el mayor esfuerzo recaudatorio no tendrá los efectos deseados en la reducción de la pobreza, si no existe una adecuada ejecución del gasto. Para evaluar la eficiencia del gasto en la ciudad, se acude al Índice de Transparencia de las entidades públicas calculado por la Corporación Transparencia por Colombia. Este índice analiza tres características vitales en la administración pública para controlar los riesgos de corrupción: 1) visibilidad, entendida como la capacidad 


\section{GRÁFICO 24}

Santa Marta: Recursos adicionales con aumento de eficiencia, $2019-2030$

a. Miles de millones de pesos
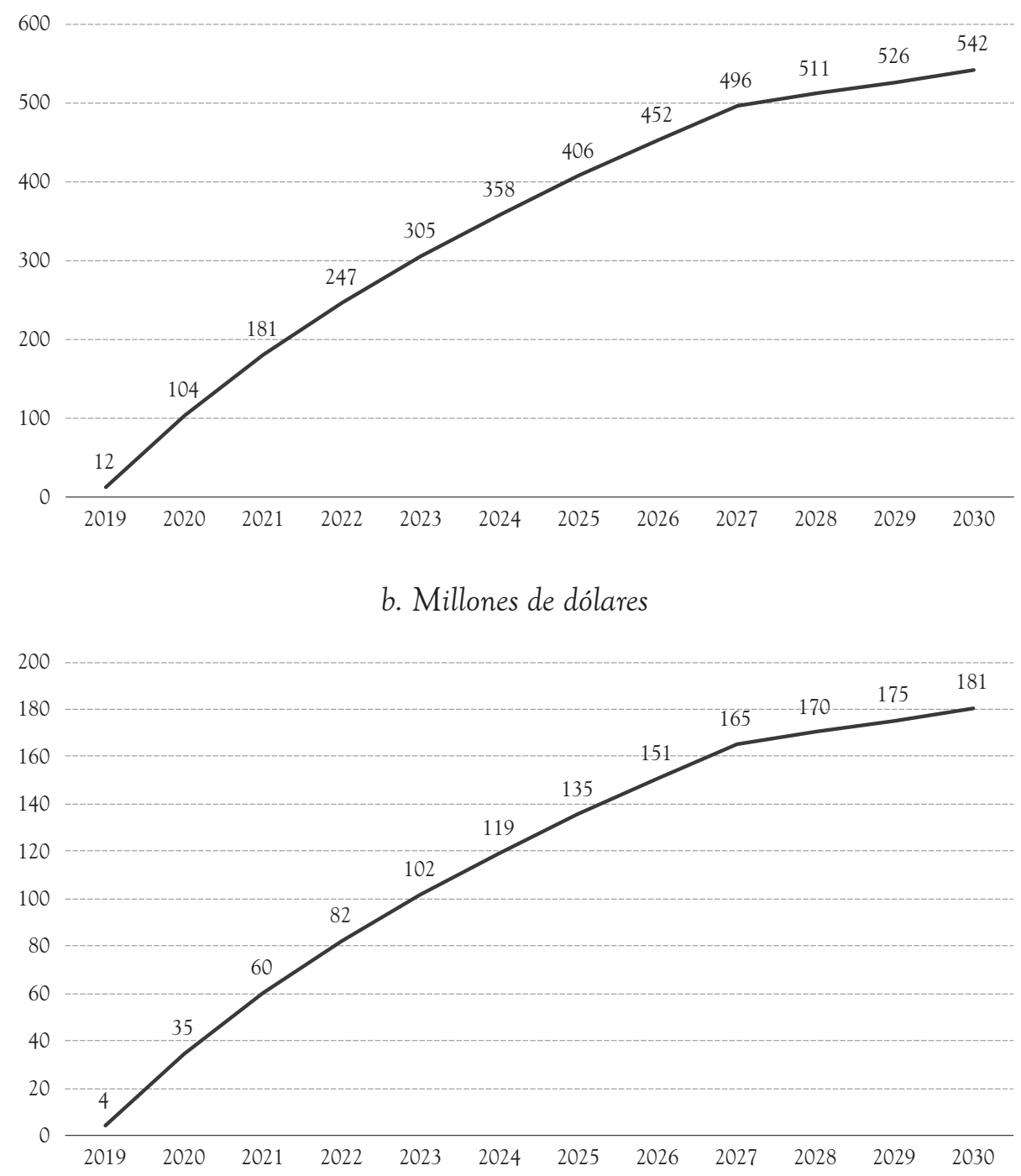

Fuentes: Elaboración propia con base en Bonet-Morón y Pérez-Valbuena (2017). 
de una entidad para hacer públicas sus políticas, procedimientos y decisiones; 2) institucionalidad, como el cumplimiento de normas y estándares establecidos para los procesos de gestión; y 3) control y sanción, referente a la capacidad para generar acciones de control y sanción mediante procesos internos.

El Gráfico 25 muestra el Índice de Transparencia de las Alcaldías de las ciudades principales e intermedias. La Alcaldía de Santa Marta ocupa el último lugar con un índice de 38, que la categoriza con un nivel de riesgo muy alto. Este resultado indica que es indispensable el aumento de la transparencia en la ciudad. Sin esto, las propuestas presentadas a lo largo de este trabajo no contarán con el potencial para erradicar la pobreza en la ciudad.

En síntesis, los distintos indicadores presentados muestran que Santa Marta cuenta con posibilidades de incrementar sus recursos. En este caso, aumentando la eficiencia en el recaudo de ingresos propios y mejorando la transparencia en la ejecución del gasto. No obstante, también existen otras alternativas que podrían apoyar el financiamiento de estas inversiones, tales como recursos del Presupuesto General de la Nación, transferencias del nivel nacional y regalías. Incluso, teniendo en cuenta las repercusiones que tuvo el conflicto armado en Santa Marta, se podría considerar el uso de recursos del posconflicto.

\section{GRÁFICO 25}

Ciudades principales e intermedias de Colombia:

Índice de transparencia, 2015 - 2016

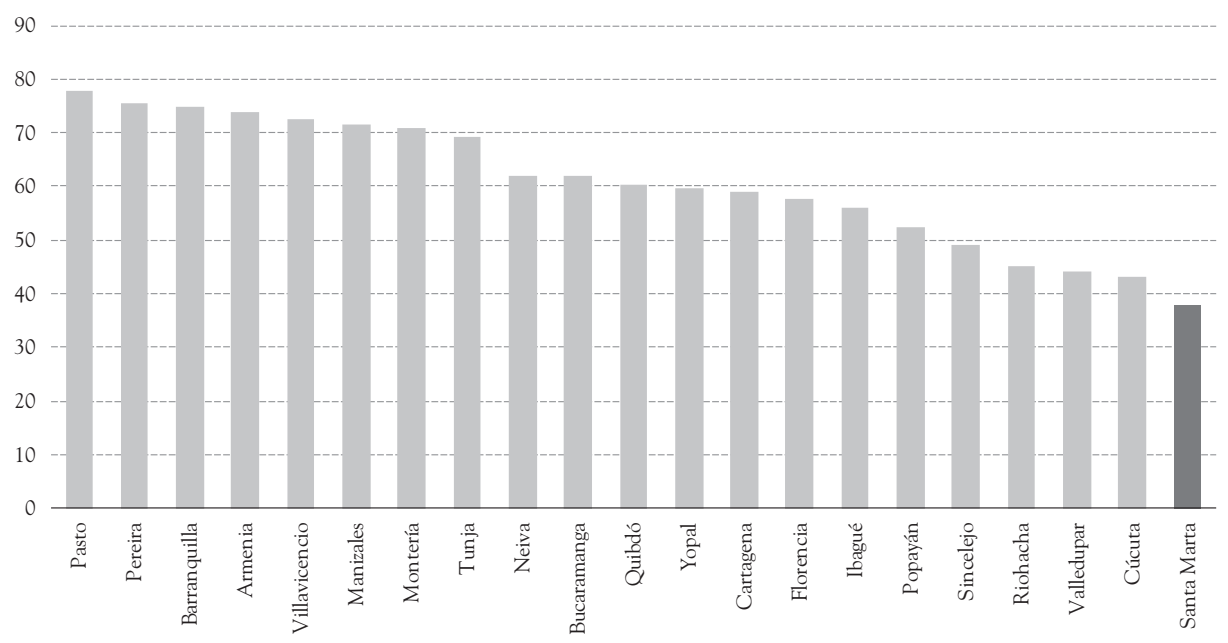

Fuente: Corporación Transparencia por Colombia. 


\section{CONCLUSIONES}

Hace unas tres décadas Santa Marta tenía la pobreza más baja entre las grandes ciudades portuarias del Caribe colombiano. En el Censo de 1985, la pobreza medida por NBI era de 42\% en Cartagena, 37\% en Barranquilla, y de 33\% en Santa Marta. En 2005, dos décadas después, el mismo indicador reveló una incidencia de este fenómeno en Cartagena y Barranquilla de 26\% y 18\%, respectivamente. Por su parte, el de Santa Marta fue de 29\%. Mientras Barranquilla y Cartagena redujeron en este lapso su pobreza en cerca de 19 pp y 16 pp, respectivamente, el avance en Santa Marta fue de solo 4 pp.

Un factor principal que explica el deterioro relativo de Santa Marta en materia de pobreza fue la enorme llegada de desplazados desde la década de 1990, debido a la violencia generada por la guerrilla y los paramilitares. Entre todas las ciudades de Colombia, en términos absolutos, solo Bogotá y Medellín recibieron más desplazados que Santa Marta.

Los indicadores presentados revelan, además, la incapacidad del gobierno para atender las demandas de bienes y servicios básicos de esta población. El resultado de la inadecuada respuesta fue la aparición de cinturones de miseria en las faldas de los cerros que rodean la ciudad y en otras zonas del casco urbano. Barrios como María Cecilia en la Localidad 1, el Cerro de las Tres Cruces en la Localidad 2 y el barrio Cristo Rey en la 3, además de alojar un gran número de pobres, presentan incidencias de este fenómeno superiores al 90\%.

Además de la necesidad de ampliar la cobertura y calidad de los servicios públicos, especialmente de agua potable, y reducir el déficit de vivienda, el gran reto de Santa Marta en la actualidad es mejorar su sistema educativo. La infraestructura escolar es insuficiente e inadecuada, la capacitación de los maestros baja y, en general, se debe mejorar la calidad de la enseñanza pues, como lo muestran los distintos indicadores, la ciudad ocupa los últimos lugares del país a este respecto. Por ejemplo, en las Pruebas Saber 11 de 2017, en matemáticas, entre las 23 ciudades principales e intermedias del país, los estudiantes samarios solo superaron a los de Quibdó.

Para superar el rezago educativo, se propone una inversión en cuatro aspectos específicos: jornada única, mejoramiento de infraestructura, formación de docentes en servicio y aumento de la capacidad institucional. En su totalidad, estas inversiones tendrían un costo aproximado de USD \$207 millones. Además, para llevar la pobreza de la ciudad al promedio de las 23 ciudades principales e intermedias 
en 2030, se proponen otras tres prioridades en las inversiones: reubicación de viviendas, conexión a los servicios de acueducto y alcantarillado y capacitación y vinculación laboral. Con estas últimas, el costo total de la intervención sería de usD $\$ 433$ millones.

Como se propone que las metas sean alcanzadas a 2030, se evaluaron también las posibles fuentes de recursos para financiar la inversión. Se encontró que, aprovechando el potencial recaudatorio de la ciudad, se podrían obtener recursos adicionales por USD $\$ 1.300$ millones entre 2019 y 2030. Es decir, con el esfuerzo fiscal local se puede lograr la financiación para llevar en 12 años la pobreza de Santa Marta al promedio que tendrán las 23 ciudades principales e intermedias en 2030. Lo anterior, sin olvidar que es esencial mejorar la transparencia en el manejo de los recursos para efectivamente alcanzar las metas propuestas.

\section{REFERENCIAS}

Abello, Alberto, y Silvana Giaimo (compiladores) (2000), Poblamiento ciudades del Caribe colombiano, Bogotá: Fondo Financiero de Proyectos de Desarrollo y Observatorio del Caribe Colombiano.

Aguilera Díaz, María M., y Adolfo Meisel Roca (2009), “La isla que se repite? Cartagena en el Censo de población de 2005”, Documentos de Trabajo sobre Economía Regional, No. 109, Centro de Estudios Económicos Regionales (CEER), Banco de la República.

Alcaldía Distrital de Santa Marta (2012), Plan de infraestructura escolar para el Distrito Turístico Cultural e Histórico de Santa Marta, Santa Marta: Alcaldía Distrital de Santa Marta.

Ayala García, Jhorland, y Adolfo Meisel Roca (2016), "La exclusión en los tiempos del auge: El caso de Cartagena”, Economía E⿱ Región, Vol. 10, No. 2.

Ayala García, Jhorland, y Adolfo Meisel Roca (2017), "Cartagena libre de pobreza extrema en 2033”, Documentos de Trabajo sobre Economía Regional, No. 257, Centro de Estudios Económicos Regionales (CEER), Banco de la República.

Banco Mundial (2018), Informe sobre el desarrollo mundial 2018: Aprender para hacer realidad la promesa de la educación, Washington: Banco Mundial.

Bedi, Tara, Aline Coudouel, and Kenneth Simler (2007), "Maps for Policy Making: Beyond the Obvious Targeting Applications", in Tara Bedi, Aline Coudouel y Kenneth Simler (editors), More Than a Pretty Picture: Using Poverty Maps to Design Better Policies and Interventions, Washington: The World Bank. 
Benjumea Brito, Paola (2015), "La cara desconocida de la urbanización Ciudad Equidad, en Santa Marta”, El Tiempo, 30 de agosto.

Bonet-Morón, Jaime, y Gerson Javier Pérez-Valbuena (2017), "Financiamiento y calidad del gasto en la región Caribe colombiana", Documentos de Trabajo sobre Economía Regional y Urbana, No. 262, Centro de Estudios Económicos Regionales (CEER), Banco de la República.

Bonet-Morón, Jaime, y Jhorland Ayala-García (2016), "The Territorial Fiscal Gap in Colombia”, Documentos de Trabajo sobre Economía Regional, No. 251, Centro de Estudios Económicos Regionales (CEER), Banco de la República.

Bonilla M., Leonardo, (2011), "Doble jornada escolar y calidad de la educación en Colombia”, Coyuntura Económica, Vol. XLI, No. 1.

Bonilla-Mejía, Leonardo, y Eduard F. Martínez-González (2017), "Educación para la inclusión y la transformación social en el Caribe colombiano”, Documentos de Trabajo sobre Economía Regional y Urbana, No. 263, Centro de Estudios Económicos Regionales (CEer), Banco de la República.

Bucheli, Marcelo (2005), Bananas and Business, The United Fruit Company in Colombia, 1899 - 2000, New York: New York University Press.

Cepeda Emiliani, Laura (2011), "Los sures de Barranquilla: La distribución espacial de la pobreza”, Documentos de Trabajo sobre Economía Regional, No. 142, Centro de Estudios Económicos Regionales (CEER), Banco de la República.

Concejo del Distrito Turístico, Cultural e Histórico de Santa Marta (2000), Acuerdo No. 005, "Por el cual se expide el Plan de Ordenamiento Territorial de Santa Marta 'Jate Matuna' 2000 - 2009”.

Cuervo Beatriz, Mateo Linares, Camilo Molina, Alejandro Castellanos, Simón Callejas, y Luis Hernán Sanz (2015), Santa Marta, Distrito Turístico, Cultural e Histórico. Expediente para la revisión ordinaria del POT - Componente urbano, Bogotá y santa Marta: Geografía Urbana.

Departamento Administrativo Nacional de Estadística (DANE) (2017), "Pobreza Monetaria y Multidimensional en Colombia 2016”, Boletín Técnico.

Fay, Marianne, and Anna Wellenstein (2005), "Keeping a Roof Over One's Head: Improving Access to Safe and Decent Shelter", in Marianne Fay (editor), The Urban Poor in Latin America, Washington: The World Bank.

Fay, Marianne, and Caterina Ruggeri Laderchi (2005), "Urban Poverty in Latin America and the Caribbean: Setting the Stage", in Marianne Fay (editor), The Urban Poor in Latin America, Washington: The World Bank.

Feres, Juan Carlos, y Xavier Mancero (2001), "Enfoques para la medición de la pobreza: breve revisión de literatura”, Serie Estudios Estratégicos y Prospectivos, 
No. 4, División de Estadísticas y Proyecciones Económicas, Comisión Económica para Amércia Latina (CEPAL).

Flórez, Carmen Elisa, Francisco Espinosa, y Lina María Sánchez (2008), Diseño del Índice SISBEN en su tercera versión -SISBEN III-, Bogotá: Departamento Nacional de Planeación (DNP).

Freije, Samuel (2002), "El empleo informal en América Latina y el Caribe: Causas, consecuencias y recomendaciones de política", Serie Documentos de Trabajo Mercado Laboral, Banco Interamericano de Desarrollo (BID).

Galvis, Luis Armando, y Adolfo Meisel Roca (2010), "Persistencia de las desigualdades regionales en Colombia: Un análisis espacial”, Documentos de Trabajo sobre Economía Regional, No. 120, Centro de Estudios Económicos Regionales (CEER), Banco de la República.

García, Sandra, Camila Fernández, y Christopher Weiss, "Does Lengthening the School Day Reduce the Likelihood of Early Dropout and Grade Repetition: Evidence from Colombia”, Documentos de Trabajo EgoB, No. 7, Escuela de Gobierno Alberto Lleras Camargo, Universidad de los Andes.

Gaviria Muñoz, Simón (2017), APP Acueducto y Alcantarillado en Santa Marta, Bogotá: Departamento Nacional de Planeación (DNP).

Hincapié, Diana (2016), "Do Longer School Days Improve Student Achievement? Evidence from Colombia, IDB Working Paper Series, No. IDB-Wp-679, Inter-American Development Bank.

Hosie, Simón, Pablo Said Lissa, Liliana González Rojas, Omar Cordero Durango, Luis Miguel Marín, Mariana Gil Arboleda, Ana María Palomo, Paola Macía Fernández, y Viviana Ríos Pérez (2017), Planes vivos. Pescaíto, Bogotá: Financiera del Desarrollo Territorial (FINDETER).

Instituto de Investigaciones Marinas y Costeras (INVEMAR) (2016), Evaluación de la vulnerabilidad por ANM en la zona costera del departamento de Magdalena, Santa Marta: INVEMAR.

Levitas, Ruth, Christina Pantazis, Eldin Fahmy, David Gordon, Eva Lloyd, adn Demi Patsios (2007), The Multi-Dimensional Analysis of Social Exclusion, Bristol: University of Bristol.

Meisel Roca, Adolfo (2005), "Ciénaga: La economía después del banano", en María M. Aguilera Díaz (editor), Economías locales del Caribe colombiano: Siete estudios de caso, Bogotá: Banco de la República.

Ministerio de Comercio, Industria y Turismo (Mincit), Boletín Mensual Turismo. Enero 2018, Bogotá: MinciT. 
Ministerio de Vivienda (2013), "25 barrios humildes de la capital del Magdalena se beneficiarían con conexiones intradomiciliarias", 9 de marzo de 2013, [Disponible en: http://www.minvivienda.gov.co/sala-de-prensa/noticias/2013/ marzo/2-800-familias-pobres-de-santa-marta-tendr\%c3\%A1n-ducha-sanitario-lavamanos-y-lavadero-dentro-de-sus-casas].

Morón Cárdenas, Jaime, Beethoven Herrera Valencia, Jairo Mendoza Mendoza, Alex Araque Solano, Luis Mejía Martínez (2011), Oportunidades de inclusión productiva para poblaciones en situación de pobreza y vulnerabilidad en el Distrito Turístico de Santa Marta, Santa Marta: Programa de las Naciones Unidas para el Desarrollo (PNud Colombia).

Oketch, Moses, Tristan McCowan, and Rebecca Schendel, (2014), The Impact of Tertiary Education on Development, London: Department for International Development.

Pachón, Álvaro (2012), Proyecciones de población a nivel departamental municipal agregadas por área, urbano y rural, por sexo y grupos de edad, para el período 2010 - 2050 incluyendo la totalidad del pais, Bogotá: Departamento Nacional de Planeación (DNP).

Pérez V., Gerson Javier, e Irene Salazar Mejía (2007), "La pobreza en Cartagena: Un análisis por barrios, Documentos de Trabajo sobre Economía Regional, No. 94, Centro de Estudios Económicos Regionales (CEER), Banco de la República.

Romero P., Julio (2007), “Discriminación laboral o capital humano? Determinantes del ingreso laboral de los afrocartageneros", Documentos de Trabajo sobre Economía Regional, No. 94, Centro de Estudios Económicos Regionales (CEER), Banco de la República.

Ruggeri Laderchi, Caterina (2005), “Working One's Way Up: The Urban Poor and the Labor Market", in Marianne Fay (editor), The Urban Poor in Latin America, Washington: The World Bank.

Sánchez Baute, Alonso (2008), Líbranos del bien, Bogotá: Alfagaura.

Sanghee, Jung (2017), "La pobreza urbana en América Latina y los desafíos en la era del desarrollo sustentable", PORTES, Revista mexicana de estudios sobre la Cuenca del Pacifico, Vol. 11, No. 21.

Sen, Amartya (1984), "The Living Standard", Oxford Economic Papers, Vol. 36.

Superintendencia de Servicios Públicos Domiciliarios (Superservicios) (2017), Evaluación integral de prestadores, Compañia del Acueducto y Alcantarillado Metropolitano de Santa Marta S.A. E.S.P., Bogotá: Superintendencia de Servicios Públicos Domiciliarios. 
Viloria de la Hoz, Joaquín (2014), Empresarios del Caribe colombiano: Historia económica y empresarial del Magdalena Grande y del Bajo Magdalena, 1870 - 1930, Bogotá: Banco de la República.

Weller, Jürgen (2004), "El empleo terciario en América Latina: Entre la modernidad y la sobrevivencia, Revista de la Cepal, No. 84.

World Health Organization (2017), Un-Water Global Analysis and Assessment of Sanitation and Drinking-Water (gLAAS) 2017 Report: Financing Universal Water, Sanitation and Hygiene under the Sustainable Development Goals, Geneva: World Health Organization (wHO). 


\section{ANEXOS}

\section{ANEXO 1}

Santa Marta: Porcentaje de viviendas sin acceso a servicio de acueducto por barrio, 2011

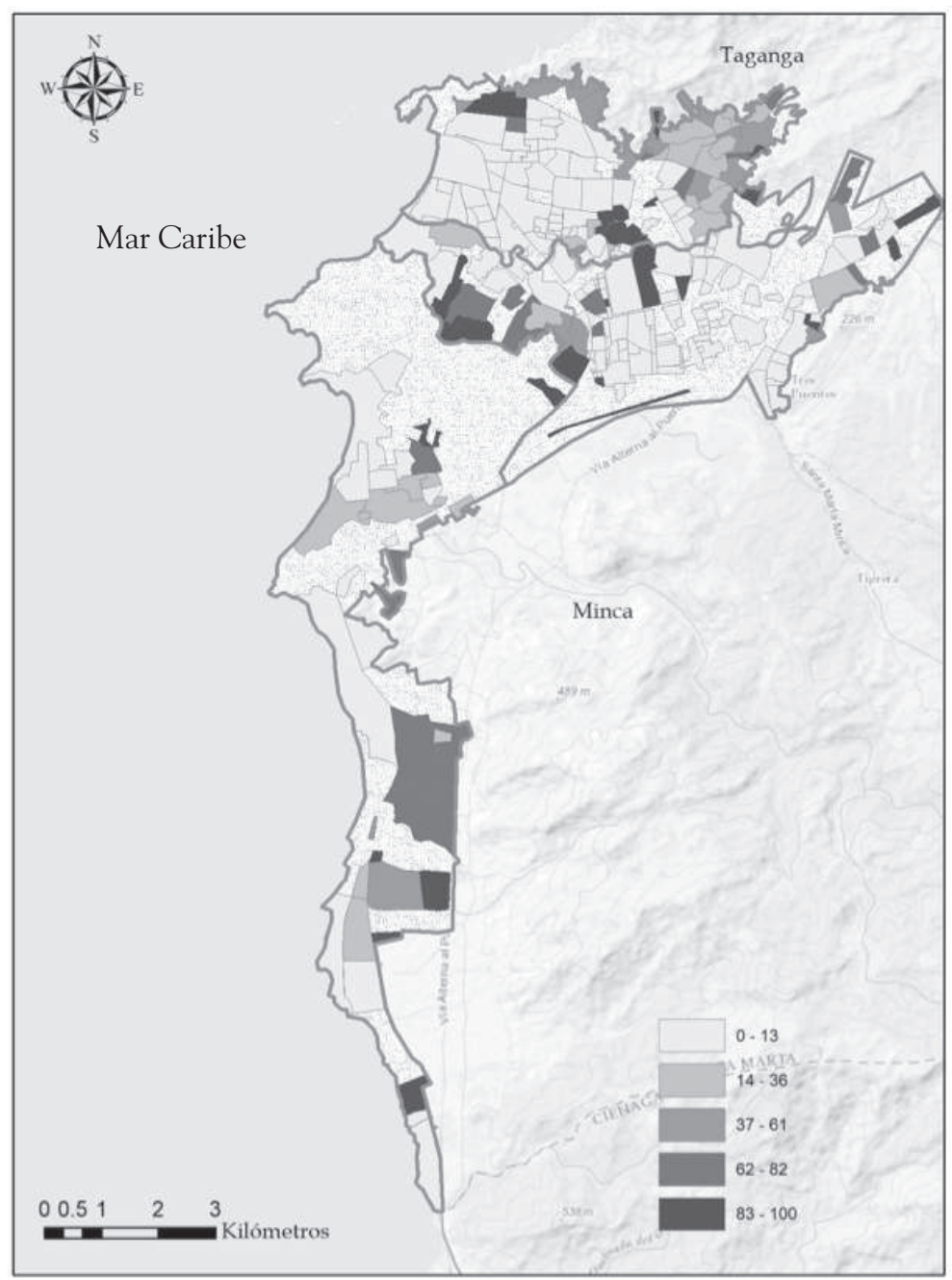

Fuentes: Elaboración propia con base en datos de la Secretaría de Planeación Distrital de Santa Marta y del SISBEN. 


\section{ANEXO 2}

Santa Marta: Porcentaje de viviendas sin acceso a servicio de alcantarillado por barrio, 2011

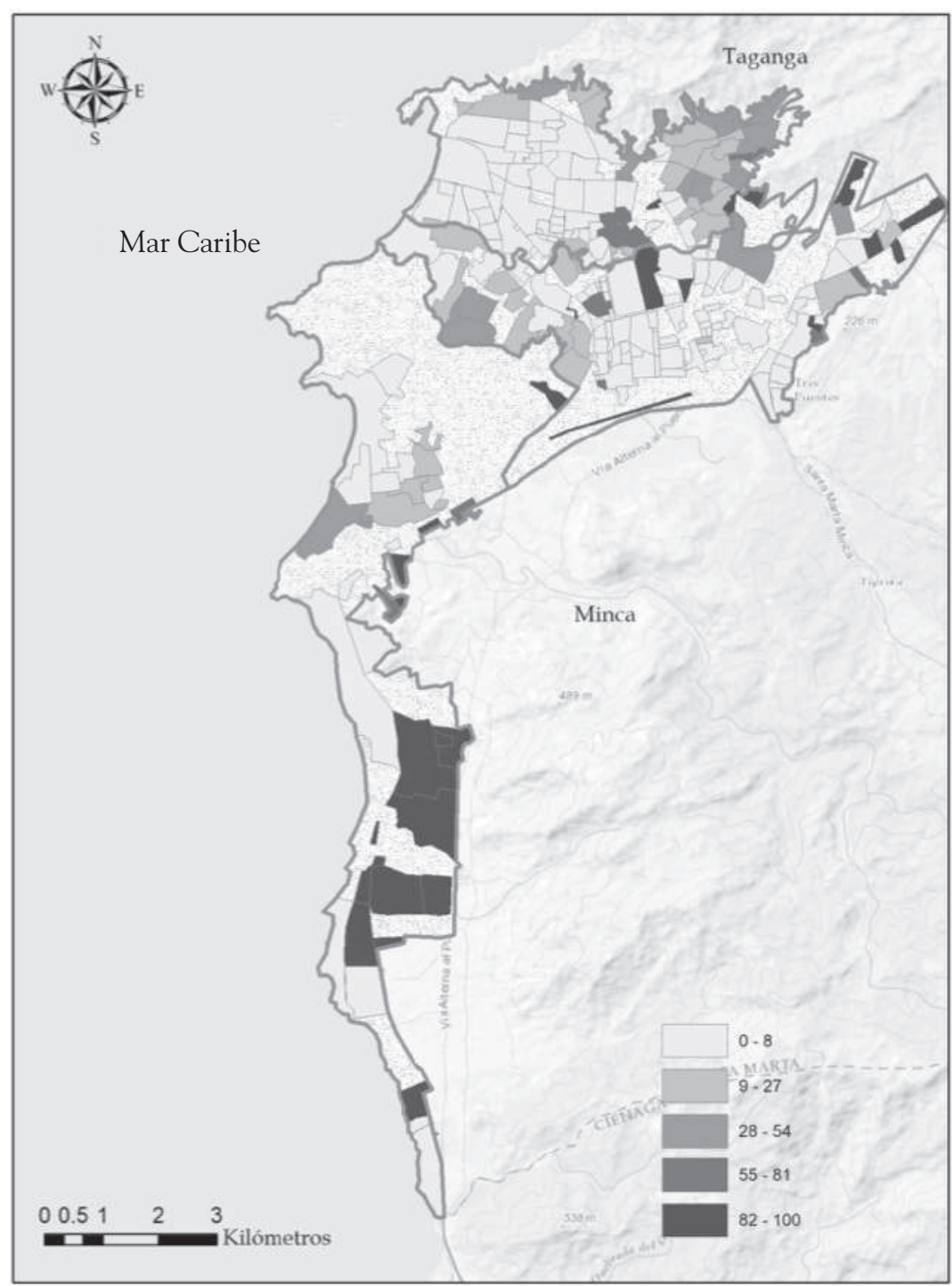

Fuentes: Elaboración propia con base en datos de la Secretaría de Planeación Distrital de Santa Marta y del SISBEN. 


\section{ANEXO 3}

Santa Marta: Porcentaje de viviendas sin acceso a servicio de acueducto en los corregimientos de la zona rural, 2011

\begin{tabular}{|l|c|c|}
\hline Corregimiento & $\begin{array}{c}\text { Número de viviendas sin } \\
\text { servicio de acueducto }\end{array}$ & $\begin{array}{c}\text { Porcentaje del total } \\
\text { de viviendas }\end{array}$ \\
\hline Minca & 903 & 99,7 \\
\hline Taganga & 827 & 92,7 \\
\hline Guachaca & 3.463 & 99,2 \\
\hline
\end{tabular}

Fuentes: Elaboración propia con base en datos del SISBEN.

\section{ANEXO 4}

Santa Marta: Porcentaje de viviendas sin acceso a servicio de alcantarillado en los corregimientos de la zona rural, 2011

\begin{tabular}{|l|c|c|}
\hline Corregimiento & $\begin{array}{c}\text { Número de viviendas sin } \\
\text { servicio de alcantarillado }\end{array}$ & $\begin{array}{c}\text { Porcentaje del total } \\
\text { de viviendas }\end{array}$ \\
\hline Minca & 901 & 99,4 \\
\hline Taganga & 885 & 99,2 \\
\hline Guachaca & 3.414 & 97,8 \\
\hline
\end{tabular}

Fuentes: Elaboración propia con base en datos del SISBEN. 